\title{
Wheel and Deal in the Mitochondrial Inner Membranes: The Tale of Cytochrome $c$ and Cardiolipin
}

\author{
Antonio Díaz-Quintana $\mathbb{D}^{\mathrm{D}}$, Gonzalo Pérez-Mejías $(\mathbb{D}$, Alejandra Guerra-Castellano, \\ Miguel A. De la Rosa, and Irene Díaz-Moreno
}

\begin{abstract}
Instituto de Investigaciones Químicas (IIQ), Centro de Investigaciones Científicas Isla de la Cartuja (cicCartuja), Universidad de Sevilla - Consejo Superior de Investigaciones Científicas (CSIC), Avda. Américo Vespucio 49, Seville 41092, Spain
\end{abstract}

Correspondence should be addressed to Antonio Díaz-Quintana; qzaida@us.es and Irene Díaz-Moreno; idiazmoreno@us.es

Received 29 July 2019; Accepted 28 February 2020; Published 22 April 2020

Guest Editor: Armen Y. Mulkidjanian

Copyright ( 2020 Antonio Díaz-Quintana et al. This is an open access article distributed under the Creative Commons Attribution License, which permits unrestricted use, distribution, and reproduction in any medium, provided the original work is properly cited.

Cardiolipin oxidation and degradation by different factors under severe cell stress serve as a trigger for genetically encoded cell death programs. In this context, the interplay between cardiolipin and another mitochondrial factor-cytochrome $c$-is a key process in the early stages of apoptosis, and it is a matter of intense research. Cytochrome $c$ interacts with lipid membranes by electrostatic interactions, hydrogen bonds, and hydrophobic effects. Experimental conditions (including $\mathrm{pH}$, lipid composition, and post-translational modifications) determine which specific amino acid residues are involved in the interaction and influence the heme iron coordination state. In fact, up to four binding sites $(\mathrm{A}, \mathrm{C}, \mathrm{N}$, and $\mathrm{L}$ ), driven by different interactions, have been reported. Nevertheless, key aspects of the mechanism for cardiolipin oxidation by the hemeprotein are well established. First, cytochrome $c$ acts as a pseudoperoxidase, a process orchestrated by tyrosine residues which are crucial for peroxygenase activity and sensitivity towards oxidation caused by protein self-degradation. Second, flexibility of two weakest folding units of the hemeprotein correlates with its peroxidase activity and the stability of the iron coordination sphere. Third, the diversity of the mode of interaction parallels a broad diversity in the specific reaction pathway. Thus, current knowledge has already enabled the design of novel drugs designed to successfully inhibit cardiolipin oxidation.

\section{Introduction}

Mitochondria-the so-called powerhouses of the cell-are responsible for a broad assortment of metabolic processes. Their key role in cells is reflected by the cornucopia of proteins involved in its function. In total, more than 1150 genes related to organelle function are recorded in the human MitoCarta. Furthermore, 1 in every 5000 people are effected by a mitochondrial disorder [1].

Mitochondria play a significant role in cell homeostasis by helping to modulate cell signaling pathways. On one hand, the activity of the electron transport chain (ETC) is related to the release of reactive oxygen species (ROS) [2] which are strong modifiers of cell constituents such as proteins, nucleic acids, and lipids. Dysregulation of ROS can lead to oxidative stress which in turn can initiate cell death programs $[3,4]$, in which lipid peroxidation and their products play a key role [5].

Cardiolipin (CL) oxidation by cytochrome $c(\mathrm{Cc})$ at the onset of apoptosis is a decisive step [6]. During homeostasis, the soluble cationic hemeprotein is located in the mitochondrial intermembrane space, shuttling electrons between complexes III (CIII) and IV (CIV) in the ETC. Indeed, Cc is a key Janus catalyst of CL signaling rather than a passive messenger. Its ability to oxidize superoxide anions $\left(\mathrm{O}_{2}^{-\bullet}\right)$ to molecular $\mathrm{O}_{2}$ along with its peroxidase activity in solution reduce the damage caused by oxidative stress [7-12]. However, rearrangement of the mitochondrial membrane triggered by $\mathrm{t}$ Bid upon severe stress makes CL available to bind $\mathrm{Cc}$ [13] on the outer leaflet of the IMM. Thus, acyl chains of CL are oxidized due to the oxygenase activity of the hemeprotein [14]. In fact, oxygenase activity of $\mathrm{C} c$ rises substantially in 
Cc-CL complexes [15]. Subsequent CL oxidation favors the release of $\mathrm{C} c$ into the cytosol where it triggers apoptosis [16-18]. Furthermore, an array of products from Cc-mediated CL oxidation-e.g., hydroxy-, oxo-, and peroxipolyunsaturated fatty acids - act as cell fate decision signals [19].

Although major features of cell death signaling pathways converging on CL metabolism have been thoroughly characterized, understanding the intimate mechanism of CL oxidation by $\mathrm{C} c$ remains challenging. Both CL-containing membranes and $\mathrm{C} c$ display complex behaviors that depend on different factors, including experimental conditions and post-translational modifications (PTM) of the protein.

This review article aims to provide the readers with an overview of the interaction between $\mathrm{C} c$ and $\mathrm{CL}$ and how it affects the peroxidase and oxygenase activities of the hemeprotein. Particular emphasis will be made on the conformational plasticity of $\mathrm{C} c$, which enables its Janus functionality. In addition, we will discuss free oxidation of $\mathrm{CL}$, regulation of $\mathrm{Cc}$ activity, and its relationship with a diverse range of human diseases and recent strategies to combat them.

\section{Cardiolipin: Properties and Role in the Mitochondrial Membranes}

Cardiolipins (1,3-bis(sn-3' -phosphatidyl)-sn-glycerol) are a group of anionic phospholipids found in the plasma membrane of various bacteria and the inner mitochondrial membrane of eukaryotic cells [20]. These lipids contain two 1,2-diacyl-sn-glycero-3-phos-phoryl moieties bridged by a glycerol molecule. The two phosphatidyl groups are stereochemically nonequivalent, being respectively in pro$R$ and pro-S positions with respect to carbon 2 in the bridge [21]. The presence of 4 acylation sites-a fifth one at the central carbon of the glycerol bridge is also possible-would be consistent with a diverse range of CL species according to the distinct acyl chains available in a given organism. In humans, for instance, we would expect $14^{4} \mathrm{CL}$ derivatives. This contrasts with the rather lower diversity of CL compounds found in each organism [22].

Despite the presence of two phosphate groups in CL, it is thought that the single anionic species predominates. In this species, one proton is shared through a bicyclic resonance structure involving the central hydroxyl group [23]. In membranes, the glycerol hydroxyl forms intra- and interlipid hydrogen bonds with oxygen atoms from phosphate, not with carbonyl groups [24]. Early measurements of ionization constants yielded a first $\mathrm{p} K_{\mathrm{A}}$ value of 2.8 and a second one in the range between 7.5 and 9.5. A recent fourier transform infrared spectroscopy (FT-IR) analysis on liposomes also suggests two ionization steps with $\mathrm{p} K_{\mathrm{A}}$ values 4.7 and $7.9[25,26]$. Density functional theory level computations indicate a wide gap between the two $\mathrm{p} K_{\mathrm{A}}$ values [27]. Other results indicate the opposite: both behave as strong dibasic acids with $\mathrm{p} K_{\mathrm{A}}$ values within the $\mathrm{pH}$ range 2-3 in solution [28] and membrane preparations $[29,30]$. According to this data, membrane-embedded $\mathrm{CL}$ carries two negative charges at physiological $\mathrm{pH}$ values.
The behavior of CL-containing membranes is complex and strongly dependent on the composition [31] and experimental/simulation conditions [32]. For instance, the selected CL protonation state in deterministic simulations can influence results. Thermodynamic analyses with lipid mono- and bilayers indicate a decrease in the area compressibility modulus [33]. According to molecular dynamics (MD) simulations, their thickness-measured as interphosphate distances-decreases with CL content, as the electron density does [24, 34]. Furthermore, small-angle X-ray scattering (SAXS) and neutron scattering (SANS) have confirmed that CL-containing bilayers have a lower thickness. This may reflect the smaller head-group volume per phosphate. However, these membranes show larger distances between electron density maxima and a thicker hydrocarbon moiety [24]. Comparison of different MD trajectories of bilayers with PDB files suggests conformational selection takes place when CLs bind to membrane proteins [34]. The negative charge of $\mathrm{CL}$ and its four acyl groups strongly affect the phase preference of the lipid, which varies from lamellar $(\mathrm{L} \alpha)$ to inverted hexagonal $\left(\mathrm{H}_{\mathrm{II}}\right)$ depending on $\mathrm{pH}[30,32]$.

$\mathrm{CL}$ is essential for the functionality of mitochondrial membranes and processes taking place therein-e.g., protein import and electron transport [6]. It represents between 5\% and $20 \%$ of the total lipid content of the inner mitochondrial membrane (IMM) and is more abundant in the internal leaflet $[35,36]$ (Figure 1(a)). CL acts on membrane components of the ETC, aiding the assembly of the so-called respiratory supercomplexes [37, 38]. Supercomplexes modulate the performance of mitochondrial electron transport and oxidative phosphorylation [39]. Reportedly, CL is able to trap protons $[40,41]$, and it has been hypothesized to be important in the mechanism of CIII and IV acting as a proton exchanger [42-44]. The absence and/or modification of CL cause the development of several pathologies such as Barth's syndrome [37, 45-48]. Indeed, alteration of the IMM due to a decrease in the content of CL disrupts the ETC, increasing the generation of ROS [49] (Figure 1(b)). Remarkably, CL can be oxidized directly by ROS such as hydroxyl radicals and singlet oxygen, acting the products as proapoptotic signals [50].

$\mathrm{CL}$ is a mitochondrial stress-signaling factor in mitophagy and both the intrinsic and extrinsic apoptotic pathways $[6,51]$. Under stress conditions (e.g., treatment with rotenone, staurosporine or cyclosporine $\mathrm{A}$, and autophagic or apoptotic stimuli), CL molecules flip from the IMM to the outer mitochondrial membrane (OMM) [52-54] (Figure 1(b)). When eliciting the extrinsic apoptotic pathway in lymphoblastoid cells (type II cells) derived from Barth's syndrome patients and tafazzin knock-down HeLa cells, CL microdomains on the OMM recruit procaspase- 8 to promote its activation $[55,56]$. When caspase- 8 becomes active, it cleaves the proapoptotic factor Bid, a BH3-only member of the Bcl-2 family [56]. The active C-terminal fragment of the Bid (t-Bid) targets CL or its degradation product monolyso-CL (MLCL) in mitochondria [57-60] and promotes OMM permeabilization [61]. During this process, the peroxidase activity of $\mathrm{C} c$ results in the 


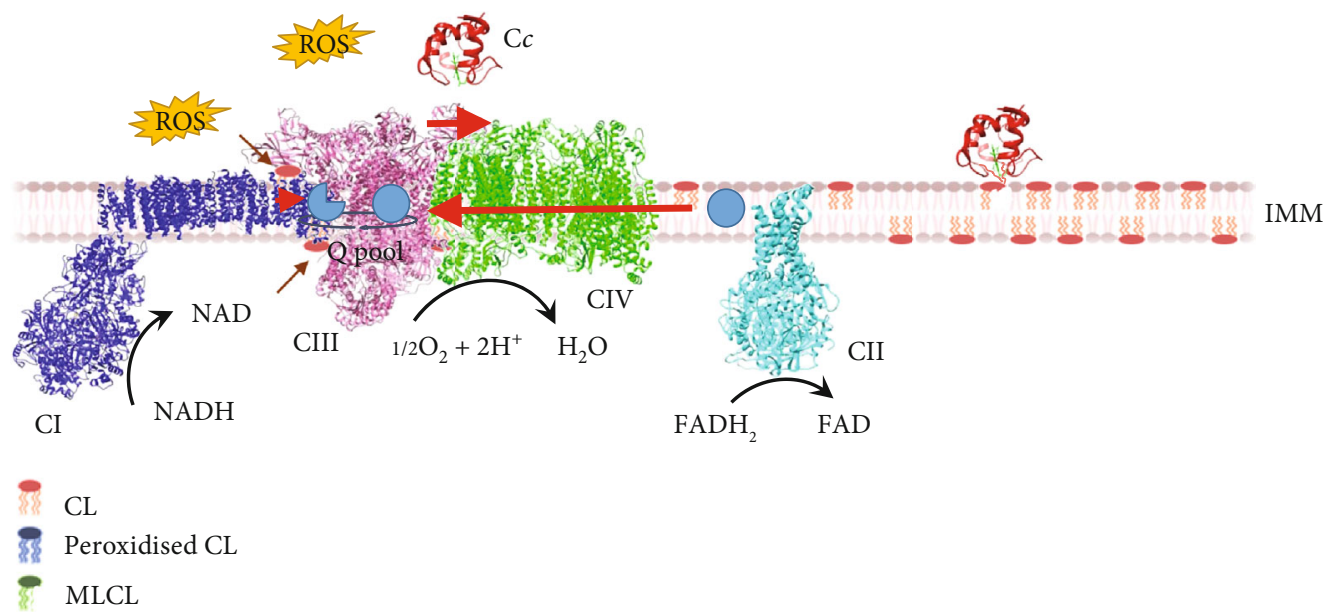

(a)
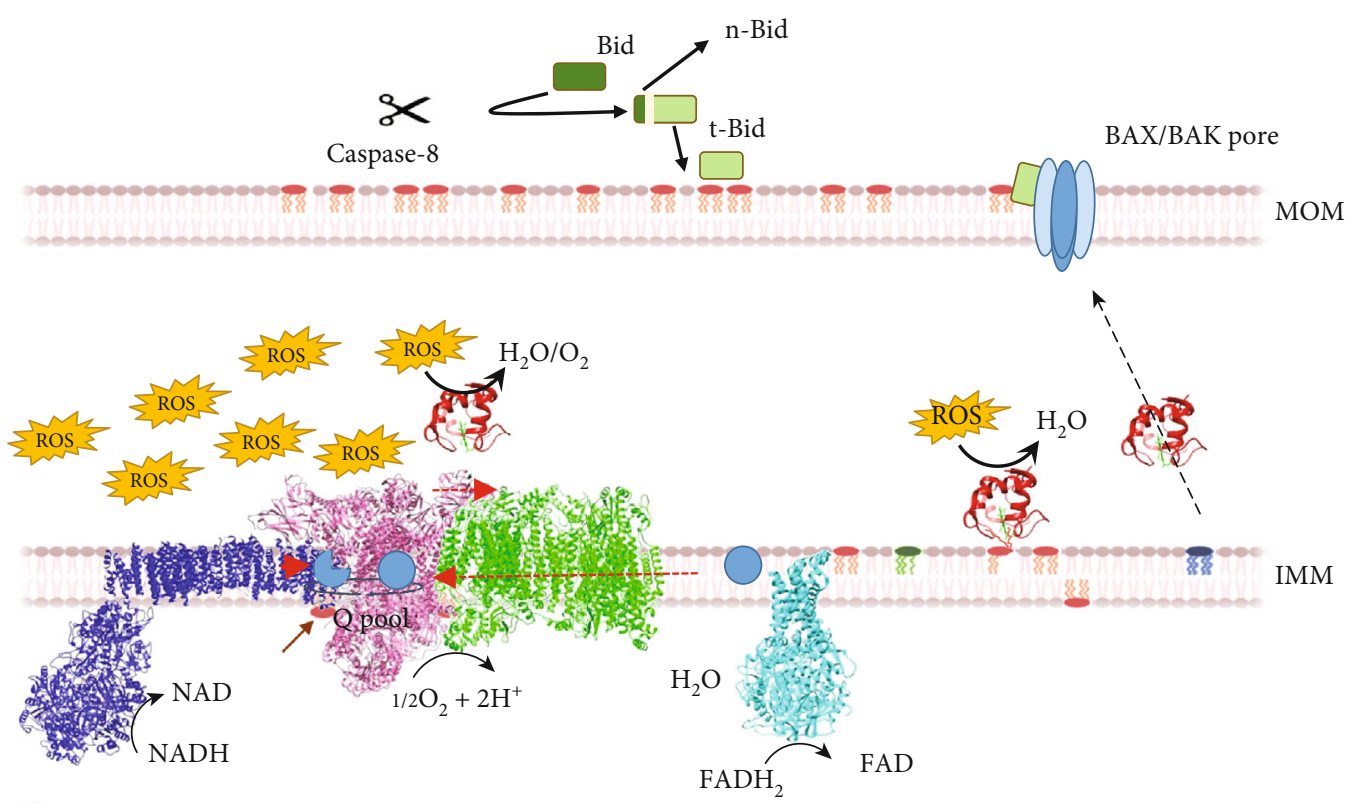

CL
Peroxidised CL
MLCL

(b)

FIgURE 1: Role of cardiolipin in cell homeostasis and apoptosis. (a) Under homeostatic conditions, cardiolipin (CL) facilitates the assembly of respiratory supercomplexes (brown arrows) and maintains a population of $\mathrm{Cc}$ bound to the inner mitochondrial membrane (IMM). The efficiency of electron transfer is high (thick red arrow). (b) Under apoptotic stimuli, procaspase-8 is recruited to CL-enriched microdomains in the outer mitochondrial membrane (OMM). The activation of caspase- 8 involves cleavage of the BID proapoptotic factor into two domains, namely, the $\mathrm{N}$-terminal (n-Bid) and C-terminal fragments ( $\mathrm{t}$-Bid). Dissociation of these two fragments is required for the interaction of $\mathrm{t}$-Bid with $\mathrm{CL}$. Then, $\mathrm{t}$-Bid promotes the formation of mitochondrial pores by assembling BAX-BAK oligomers. At the same time, ROS production increases and $\mathrm{C} c$ acts as a ROS scavenger and pseudoperoxidase. Cc peroxidase activity results in oxidation of CL acyl chains, to which the hemeprotein is anchored, freeing Cc from the IMM, facilitating its subsequent release into the cytosol upon OMM permeabilization. The efficiency of electron transfer is low (dashed red arrow). In addition, CL can be degraded in part, losing one of its acyl chains, giving rise to monolysocardiolipin (MLCL).

oxidation of CL (to which it is anchored) facilitating the release of $\mathrm{C} c$ from the IMM and subsequent massive release into the cytosol at the onset of apoptosis $[18,62]$. Extramitochondrial $\mathrm{C} c$ molecules interact with a variety of targets in the cytosol and nucleus, leading to a point of no return in the programmed cell death regulation [63-77].

\section{Cytochrome $c$ Binds Cardiolipin: A Tale of Grooves, Cavities, and Melting}

$\mathrm{C} c$ belongs to the class I single-heme cytochrome $c$ family, displaying the four typical $\alpha$-helices conserved in the whole domain family [78]. In addition, $\mathrm{C} c$ displays three $\Omega$-loops, 


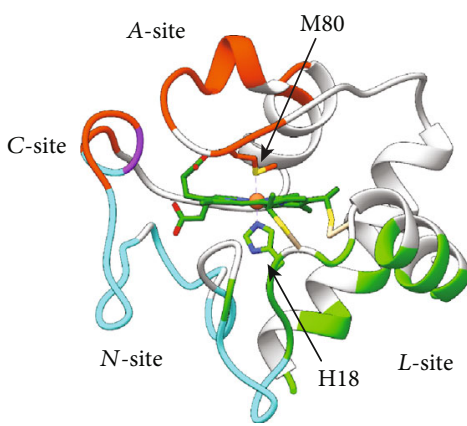

(a)

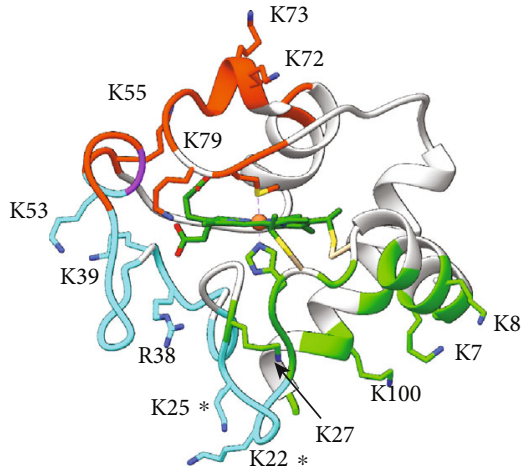

(b)

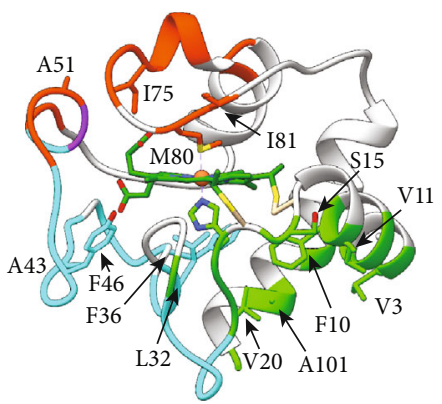

(c)

Figure 2: Cardiolipin-binding sites in cytochrome $c$. (a) Ribbon representation of oxidized human Cc (PDB 2N9J) [92]. CL-binding sites are highlighted in orange ( $A$-site or distal productive), green ( $L$-site or proximal productive), purple ( $C$-site), and cyan $(N$-site or proximal unproductive). The heme axial ligands H18 and M80 are highlighted as well. (b) Side chain representation of the positively charged Cc residues involved in the formation of the $\mathrm{C} c$-CL complex. Residues marked with an asterisk are reported to constitute the $L$ - and $N$-sites. (c) Side chain representation of hydrophobic $\mathrm{C} c$ residues, which ensure the tight interaction between $\mathrm{C} c$ and $\mathrm{CL}$ acyl chains.

two of them providing axial ligands for the heme iron. His 18 at the proximal side of the heme provides the imidazole ligand conserved among the class I family. At physiological $\mathrm{pH}$ values, Met80 thioether acts as a distal ligand. The heme porphyrin ring is covalently bound to the protein backbone by thioether bonds between the vinyl groups of the porphyrin and conserved cysteine residues in the CXXCH motif. For human $\mathrm{C} c$, conserved cysteine residues are Cys14 and Cys17. According to hydrogen exchange (HX) experiments, the apparently simple structure hides five folding units (called foldons) with different stabilities [79]. The most stable one (I) comprises the $\mathrm{N}$ - and C-terminal $\alpha$-helices. Foldon II comprises $\Omega_{\mathrm{I}}$ (from Thr19 to Phe36) and $\alpha$-helix 3, which comes before $\Omega_{\text {III }}$. Foldon III (a.k.a. neck) comprises two short amino acid stretches with an extended conformation flanking the $\Omega_{\mathrm{II}}$-loop. Notably, the latter faces heme propionates and is the least stable foldon $(\mathrm{V})$, followed by the $\Omega_{\mathrm{III}}$ region (IV) containing Met80.

The low stability of the loop containing Met80, comprising the sixth iron ligand, has a crucial role in $\mathrm{C} c$ physiology. Recent ultrafast X-ray spectroscopy analyses have highlighted the weakness of the Met80- $\mathrm{S}_{\delta}-\mathrm{Fe}^{+2}$ bond and the lack of stability $\left(4 \mathrm{~kJ} \mathrm{~mol}^{-1}\right)$ provided by the protein matrix, most likely via hydrogen bonding [80].

At physiological $\mathrm{pH}, \mathrm{Cc}$ has a net charge of +8 from its unevenly distributed ionizable groups [81, 82]. This favors interactions with negatively charged molecules, such as the polar head of phospholipids, including CL. This interaction was first analyzed by Kimelberg and Lee, using lecithin-CL vesicles [83]. Their analysis together with early HX measurements by solid-state nuclear magnetic resonance (ssNMR) indicated that $\mathrm{C} c$ preferentially binds with CL [84]. They also suggested that during this interaction, CL destabilizes or unfolds the hemeprotein. Further relaxation time measurements by ${ }^{31} \mathrm{P}$ NMR showed that $\mathrm{C} c$ impacts $\mathrm{CL}$ dynamics [85]. Surface plasmon resonance and electrochemical experiments on planar lipid bilayers allowed Salamon and Tollin to propose a two-step mechanism [86-88]. According to their proposal, $\mathrm{C} c$ first binds to membranes through electro- static interactions and, subsequently, through hydrophobic interactions to promote changes in both the structure of $\mathrm{Cc}$ and the membrane. Then, electron paramagnetic resonance (EPR) and magnetic circular dichroism (MCD) analyses showed that $\mathrm{C} c$ undergoes structural changes which affect $\mathrm{Fe}$ coordination and result in the appearance of a radical at high liposome concentrations [89]. Hence, mixing $\mathrm{C} c$ with lipids may yield several species, found in recent fluorescence anisotropy analyses [90].

Apparently at odds with this proposed model, paramagnetic-quenching EPR experiments on horse heart $\mathrm{C} c$, spin-labelled at different lysine positions, indicated that the hemeprotein can weakly interact with 1,2-dioleoyl-snglycero-3-phosphoglycerol (DOPG) bilayers [91]. This study highlighted three lysine residues at $\Omega_{\mathrm{III}}(\mathrm{K} 72, \mathrm{~K} 86$, and K87, a.k.a $A$-site; Figure 2(a)) adjacent to the DOPG membrane. Further fluorescence studies using vesicles containing fluorescent lipid probes identified a secondary CL-binding site at low $\mathrm{pH}$ values [93]. Contrary to the $A$-site, CL association at this novel region (a.k.a. $C$-site; Figure 2(a)) is unaffected by ionic strength or the presence of ATP. Data suggested CL binds to this site via hydrogen bonds at N52, and a single acyl chain of the phospholipid inserts into a nearby hydrophobic pocket while the others remain in the bilayer [94]. This proposed interaction mechanism is known as the extended lipid anchorage model and is supported by studies on the ability of natural and engineered phospholipids to quench the fluorescence of Zn-substituted Cc [95, 96]. Consistently, a N52I mutation heavily impacts the kinetics of the interaction between $\mathrm{C} c$ and CL in CL-containing liposomes [97].

While, a combination of lysine modification, tryptic digestion, and MALDI-TOF analysis unveiled that horse heart $\mathrm{C} c$ promotes the fusion of lipid vesicles via an interaction at a second positive patch. This region ( $L$-site) comprises $\mathrm{K} 22$, K25, K27, H26, and H33, besides the previously reported $A$ - and $C$-sites (Figure 2(a)) [98].

An additional UV-Vis analysis showed slight differences in the binding kinetics within a set of yeast $\mathrm{C} c$ mutants [99]. Based on their own data and the solution structure of 
the protein (PDB 1AKK; [100]), the authors proposed a cleft defined by the $\Omega_{\mathrm{III}}$ residues K72, K73, K86, and R91, matching $A$-site. Building on from this data, the ability of site-directed mutants of horse heart $\mathrm{C} c$ to bind CLcontaining liposomes was tested [101]. Notably, substituting K73 and K79 with asparagine alters the affinity of Cc towards these liposomes, whereas the same mutation at position 72 does not.

A common feature of these binding sites is the presence of several positively charged and hydrophobic residues (Figures 2(b) and 2(c)). In line with Tollin and Salamon's early postulates [88], the interaction between the positively charged residues of $\mathrm{Cc}$ and negatively charged phosphate groups of $\mathrm{CL}$ initiates the formation of the Cc-CL complex driven by electrostatic interactions [101-104]. After the initiation of the complex, hydrophobic $\mathrm{C} c$ residues play a key role in the interaction with CL acyl chains, thereby establishing a tight binding between $\mathrm{C} c$ and CL $[15,105]$.

A strong piece of evidence supporting the extended anchorage hypothesis is the presence of a channel formed by residues 52 to 74 in the tuna $C c$ XRD structure [81], where the highlighted cavities are only visible in the $4 \AA$ model. An attempt to manually dock CL inside the structure of horse heart $\mathrm{C} c$ yielded two acyl chains within the backbone [97]. Any assessment of clashes of these two acyl chains with internal residues was missing. Nevertheless, none of the two cavities in this structure appear in the updated structure at $1.5 \AA$ resolution (PDB 5CYT; unpublished). Hence, the extended lipid anchorage model demands that $\mathrm{C} c$ must undergo a substantial conformation change when interacting with lipid vesicles. A low-resolution analysis using monoclonal antibodies suggested that lipid-bound $\mathrm{C} c$ displayed an alkalinelike conformation [106]. The alkaline form of oxidized Cc presents a conformation different to that of the native species, which relates to an exchange between the Met thioether ligand and a Lys amine. However, to our knowledge, the only $\mathrm{Cc}$ alkaline structure available (PDB 1LMS; [107]) lacks a channel in which the acyl chain may be lodged, although the heme moiety is more accessible to solvent than the native structure. Another possibility is the formation of $\mathrm{Cc}$ oligomers by domain swapping $[108,109]$. Although these structures are highly variable depending on how the domain swapping is triggered by experimental conditions, a recent analysis has shown they are capable of encompassing an acyl chain [110]. Furthermore, Tyr67 in these structures would face $C_{11}$ of docked linoleic $\left(18: 2^{\Delta 9,12}\right)$ acid, a finding in agreement with peroxidation mechanisms. However, evidence of $\mathrm{C} c$ oligomerization in the presence of membranes remains unavailable.

Many of the studies above report the loss of the Met 80 coordination and at least partial denaturation-or transition to a molten globule state-of $\mathrm{Cc}$ when binding to CLcontaining vesicles or liposomes $[15,84,93,95-97,109-$ 111]. Aside from CL, some other lipids can elicit similar such structural changes in $\mathrm{C} c$ [105]. This makes the heme moiety more accessible to small substrates such as carbon monoxide or nitric oxide [105, 111]. Moreover, time-resolved fluorescence resonance energy transfer (trFRET) experiments show labelled residues-not previously reported to bind
$\mathrm{CL}-$ moving further away from the heme group in the presence of CL-containing liposomes [103, 112]. Furthermore, changes in the CD spectra and Trp59 fluorescence indicate unfolding of at least the lowest energy foldons. Consistent with the loss of Met80 coordination, substantial negative shifts in the midpoint potential of $\mathrm{Cc}$ are observable in the presence of lipid vesicles [113, 114]. Disruption of the Fe-Met80 bond also correlates with a substantial increase in $\mathrm{C} c$ peroxidase activity when $\mathrm{C} c$ interacts with CL-containing vesicles $[15,105,113]$. An illustration of conformational changes, adapted from Muenzner et al. [112], is available in Figure 3(a).

The current understanding of the effects of lipid binding on $\mathrm{C} c$ structure (as described above) is controversial. For instance, depending on the nature of the CL-rich membrane preparations and experimental setup, the shift in redox potential can be positive [86] or negative $[113,114]$. Recently, Wand and collaborators demonstrated that the mitochondrial crypts are concave surfaces, opposed to the convex lipoic vesicles often used in the analyses. They then analyzed the solution structure of oxidized horse heart $\mathrm{C} c$ encapsulated in reverse lipid micelles by NMR [115]. They utilized pseudocontact shifts as experimental restraints, which are highly sensitive to distances and orientation with respect to the main axes of the iron coordination sphere. An overlay of the structures of free [100] and encapsulated horse Cc [115] (PDB 1AKK [100] and 2N3B [115], respectively) are shown in Figure 3(b). Notably, the structure of $\mathrm{Cc}$ remains unaltered, and the chemical-shift perturbation map [115] resembles that observed for interactions between $\mathrm{C} c$ and its protein targets [116] and other class I single-heme cytochrome $c$ family members [117]. In fact, this patch includes a novel region ( $N$-site), not previously reported, comprising F36, G37, T58, W59, and K60, besides the known residues of the $A$ - and $L$-sites (Figure 2(a)). Surprisingly, ssNMR spectra tracking the interaction between $\mathrm{C} c$ and small unilamellar (convex) vesicles showed no feature indicating formation of either a molten globule or unfolding [118]. Consistently, solution HSQC (NMR) spectra of horse heart $\mathrm{C} c$ in the presence and absence of similar vesicles overlapped quite well [119]. Although some signals broaden, while others were displaced-as expected for this interaction-no features of unfolding are apparent. Therefore, the overall curvature or the membrane may be irrelevant for the stability of bound $\mathrm{Cc}$. Previous data on $\mathrm{Cc}$ unfolding in the presence of lipid vesicles might be reviewed in regard to membrane composition, lipid stability, and experimental setup. For instance, the dynamics of $\mathrm{C} c$ can change depending on buffer conditions [119]. Similarly, the ionization state of CL also affects $\mathrm{Cc}$ binding [120].

Understanding the entire landscape of the data requires the rationale underpinning the studies to be taken into account. An equilibrium between unbounded native $\mathrm{C} c$ species and membrane-bound populations-by either weak electrostatic interactions, hydrogen bonding, or hydrophobic interactions-can be observed. The relative weights of such populations vary with experimental conditions. Furthermore, our ability to detect different species relies on the sensitivity of each biophysical approach. As recently pointed out, 

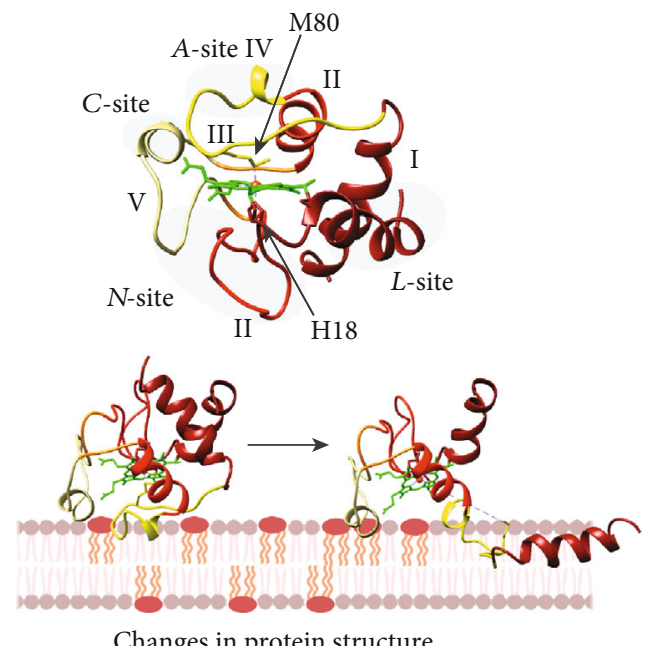

Changes in protein structure

(a)
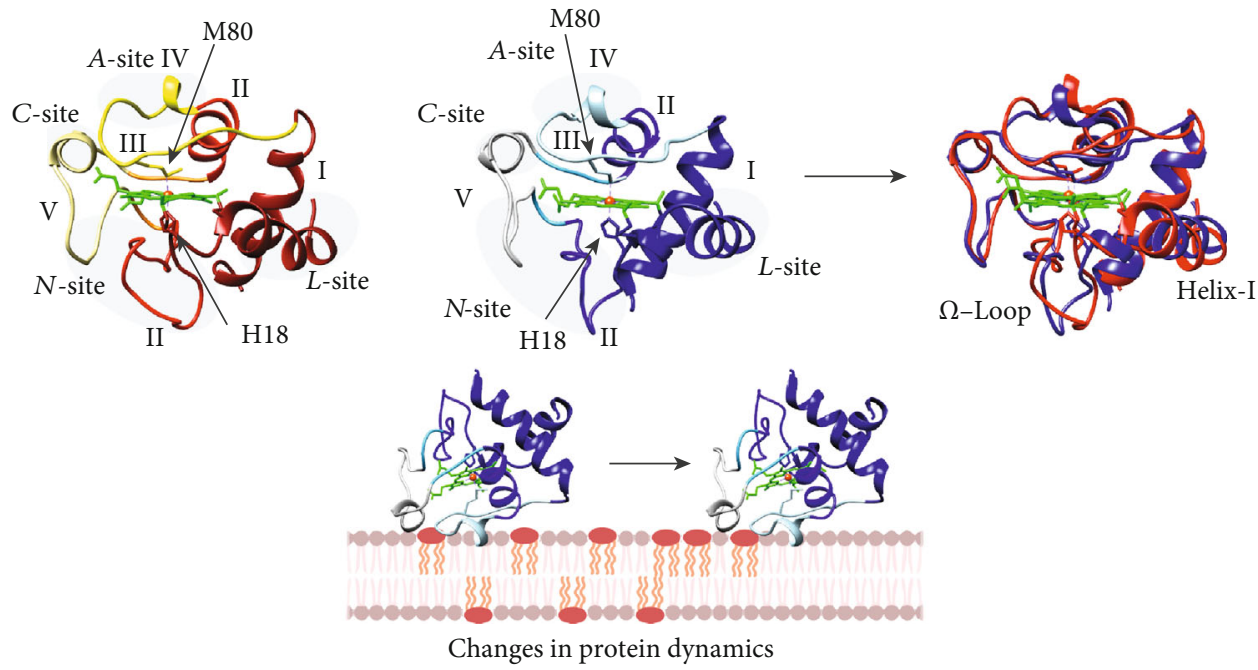

(b)

FIGURE 3: Proposed model for the interaction of cytochrome $c$ with cardiolipin at pH values above 7. (a) Upper: structure of free Cc showing the foldon units (in red scale, PDB 1AKK [100]). Lower: the Cc-CL interaction promotes unfolding of the metalloprotein and dissociation of the axial ligand M80, thus increasing accessibility to the heme crevice. (b) Upper: structural comparison of free (in red scale, PDB 1AKK [100]) and CL-bound Cc (in blue scale, PDB 2N3B [115]). Lower: interaction of Cc with CL yields a slight difference in dynamics at the level of the $\Omega$-loops and helix-I. The different foldon units of $\mathrm{C} c$ are colored as a gradient from the most stable (dark colors) to the weakest region (light colors). The heme group is in green, and the iron atom in orange.

many of the analyses above suffer from low-resolution data or the introduction of probes that could partially alter results [118]. Therefore, full understanding requires complete knowledge of experimental conditions.

\section{Interplay between Lipid and Cytochrome $c$ Dynamics: The Compact/Extended Model}

Cc can undergo several structural transitions triggered by changes in experimental conditions such as $\mathrm{pH}[89,90$, 121-123]. For example, low-spin $(S=0) \mathrm{Fe}^{\mathrm{II}}$ species may turn into high-spin $(S=2)$ species in the presence of liposomes, as shown by EPR and MCD spectroscopies [89]. Notably, ionic strength and lipid-to-protein (L/P) ratio strongly influence the populations of the distinct species
$[15,110,124,125]$. These ratios relate to lipid surface coverage by $\mathrm{C} c$ molecules $[125,126]$. At low $\mathrm{L} / \mathrm{P}$ ratios the $\mathrm{C} c$ coated micelles undergo coalescence-forming giant unilamellar vesicles-and precipitate. Whereas at moderate L/P ratios, $\mathrm{C} c$ promotes interactions between small unilamellar vesicles $[125,127]$.

The dynamic of the $\mathrm{C} c$ heme group is highly sensitive to spin state, axial ligand strength, and conformational changes. Therefore, Raman spectroscopy studies have been key in unveiling the complexity of $\mathrm{C} c$ conformation equilibria under different conditions [123, 125-128]. Hildebrandt and collaborators detected native (B1; His-Met coordination) and altered (B2) states in the presence of DOPG vesicles [125]. The B2 state comprises different species: a low-spin (B2[6cLS]), His-His-coordinated species, and two high-spin 
species (a pentacoordinated (B2 $[5 \mathrm{cHS}]$ ) and a hexacoordinated species $(\mathrm{B} 2[6 \mathrm{cHS}]))$ in which a water molecule acts as the sixth ligand. The populations of the different states change according to the $\mathrm{L} / \mathrm{P}$ ratio. The $\mathrm{B} 2$ species predominates at high $\mathrm{L} / \mathrm{P}$ ratios, whereas native $\mathrm{B} 1$ and His-Hiscoordinated B2[6cLS] coexist at lower ratios. These states are also detectable by MCD [114]. The B2 bis-Hiscoordinated species is detectable when $\mathrm{C} c$ is absorbed onto self-assembled monolayers, with and without CL [129]. At increasing concentrations of DOPC/tetraoleoylcardiolipin (TOCL) micelles, the population of bis-His species increases, as confirmed by His-by-Asn mutations and spectroscopic analyses [130].

In addition to the $\mathrm{L} / \mathrm{P}$ ratio, the content of $\mathrm{CL}$ and its composition influence $\mathrm{Cc}$ affinity and dynamics in the bound state. Fluorescence data has indeed revealed that increasing amounts of $\mathrm{CL}$ favors $\mathrm{Cc}$ binding to membranes [120]. The theoretical analysis therein suggests that the protonation state of CL may have a strong influence on populations of distinct membrane-bound $\mathrm{C} c$ species. However, the authors acknowledge that the formalism does not include the effects that $\mathrm{Cc}$ exerts on CL distribution or membrane state (see below). Indeed, kinetic investigations have shown that the exchange rate between a native-like, compact $(\mathrm{C})$ and the "extended" (E) conformations correlates with the amount of CL in the vesicles [131]. A more recent spectroscopic analysis on titration experiments by Pandiscia and Schweitzer-Stenner resulted in similar conclusions [90]. Additionally, the study highlighted that the $\mathrm{L} / \mathrm{P}$ ratio also affects the relative weight of electrostatic interactions, hydrogen bonds, and hydrophobic interactions-according to ionic strength series. In summary, besides governing $\mathrm{C} c$ conformational states, the $\mathrm{L} / \mathrm{P}$ ratio modulates the nature of bilayerprotein interactions. Notably, all the studies highlighted above hint at a rather peripheral binding model, with little or no embedding of $\mathrm{C} c$ into the membrane [90, 123, 125, $126,128,129,131]$.

On the other hand, $\mathrm{C} c$ does exert a strong influence on lipid head-group dynamics, as revealed by early ${ }^{31} \mathrm{P}$ ssNMR studies which demonstrated an increase in acyl chains dynamics and a restraint in the polar head groups of phospholipids [132, 133]. Interestingly, $\mathrm{C} c$ has little impact on the ${ }^{31} \mathrm{P}$ ssNMR "powder" spectra of dioleoyl-phosphatidylcholine (DOPC), dioleoylphosphatidylethanolamine (DOPE), or DOPC/DOPE vesicles not containing CL [134]. Indeed, NMR data strongly supported CL undergoing phase separation-to form CL rafts-within mixed DOPC/CL preparations upon the addition of $\mathrm{C} c[132,135]$. Further, freeze-fracture electron microscopy images highlighted the ability of $\mathrm{C} c$ to promote the transition of phospholipid bilayers containing CL into non-bilayer structures, including inverted tubular $\left(\mathrm{H}_{\mathrm{II}}\right)$ states $[133,134]$. A full isotropic signal in the ${ }^{31} \mathrm{P}$ ssNMR spectra of phospholipid preparations in the presence of $\mathrm{C} c$ evinced the formation of vesicular or micellar structures when the vesicles contained CL $[132,136]$. Similarly, a downfield broad signal indicated that CL mediates the formation of the $\mathrm{H}_{\mathrm{II}}$ phase upon the addition of $\mathrm{C} c$. In this sense, molecular dynamics simulations in which $\mathrm{C} c$ is in contact with a DOPC/CL mem- brane highlight the ability of this protein to recruit CL into rafts [118]. In addition, $\mathrm{Cc}$ can induce local changes in membrane curvature when the ratio of CL increases up to 20\%. Furthermore, $\mathrm{C} c$ induces pore formation in DOPC/CL giant unilamellar vesicles (GUV), as shown by confocal microscopy [137]. These pores are wide enough to allow $\mathrm{C} c$ and dextran molecules to cross the membrane.

Nevertheless, the ability of $\mathrm{C} c$ to induce membrane changes seems to be secondary regarding the activation of peroxidase activity. Addition of $\mathrm{C} c$ to large DOPC/CL unilamellar vesicles at a ca. $6 \mathrm{CL} / \mathrm{C} c$ ratio promotes peroxidase activity without substantially affecting ${ }^{31} \mathrm{P}$ ssNMR spectra or the ${ }^{13} \mathrm{C}$ frequencies of the lipid glycerol signals [138]. The major population-those accounting for less than $10 \%$ of the protein are not detectable-of $\mathrm{C} c$ in these experiments displays the same structure as the native protein in solution. Chemical-shift perturbation analysis revealed that residues affected include the $\Omega_{\mathrm{III}}$-loop and some nearby residues (including $A$-site residues). However, changes in the dynamics of the $\Omega_{\mathrm{III}}$-loop as it couples with bilayer motions are observable. This, rather than an overall unfolding, is sufficient to trigger the peroxidase activity under these conditions. In accordance with this finding, the perturbation pattern shifts when the temperature is changed or when the vesicle phospholipids are unsaturated.

The formation of $\mathrm{C} c$-CL complex requires approximately 6 molecules of CL per C c molecule $[15,112,119$, $138,139]$. The values of the apparent dissociation equilibrium constant for the $\mathrm{C} c$-CL-reduced complex are in the low micromolar range $(1.4 \mu \mathrm{M}$ at $\mathrm{pH} 8.1$ and $2.2 \mu \mathrm{M}$ at $\mathrm{pH}$ 6.5) [140], whereas in the oxidized form, they are in the high micromolar range in a two-step reaction $(20 \mu \mathrm{M}$ and $42 \mu \mathrm{M})$ [102]. Nevertheless, binding constants depend on CL composition. The affinity of $\mathrm{C} c$ towards tetrastearyl-cardiolipin-containing vesicles is several fold higher than that for TOCL ones [102], whereas tetra-myristoylcardiolipin barely interacts $\mathrm{C} c$ [15]. Notably, the measured affinities correlate well with the peroxidase activity of $\mathrm{Cc}$ in the presence of the respective vesicles, rather than the degree of unsaturation in the acyl chains [102].

\section{Cardiolipin Oxidation by Cytochrome $c$}

CL is particularly sensitive to auto-oxidation processes-those directly initiated by inducers, such as ROS. The proximity of its four unsaturated acyl chains allow "arm-to-arm" propagation, enhancing its reactivity [141]. Auto-oxidation takes place in several steps. A free radical (e.g., a ROS molecule) contains an unpaired electron, and this semioccupied orbital is a sink for a second electron. Polyunsaturated fatty acids (PUFA), such as linoleic or linolenic composing CL, are particularly sensitive to ROS-induced oxidation due to conjugative effects. Radicals such as superoxide, peroxyl ( $\left.\mathrm{ROO}^{\bullet}\right)$, or hydroxyl $\left(\mathrm{HO}^{\bullet}\right)$ sequester a hydrogen atom from the $\alpha$-methylene carbon with respect to the first ( $\mathrm{di}^{-}$) vinyl group. The resulting radical reacts immediately with $\mathrm{O}_{2}$ to generate a peroxyl radical. The variation of electron vacancy in the lipid radical underlies the diversity of reaction products. No matter how the lipid radical originates, it tends to propagate via 
a reaction with molecular oxygen, water, or other lipids. Within the process of CL signaling, there are several reactions which stand out including the addition of oxygen (to form peroxides), transfer of hydrogen atoms, addition of peroxyl radicals, and intramolecular peroxide substitution [142].

Oxidative phosphorylation and certain mitochondrial enzymes are sources of $\mathrm{O}_{2}^{-\bullet}$ radicals [143]. Superoxide is highly soluble in lipids but can be reduced within membranes by tocopherol and quinone and eliminated by superoxide dismutase (SOD), which transforms two superoxide molecules into a molecular oxygen and hydrogen peroxide [144]. In fact, enzymes like SOD, catalase, and peroxidases take part in active cell defense against oxidative stress [144]. $\mathrm{H}_{2} \mathrm{O}_{2}$ is a strong oxidant-the reduction potential for the $\mathrm{H}_{2} \mathrm{O}_{2} / \mathrm{H}_{2} \mathrm{O}$ pair is $+1.35 \mathrm{~V}$, at $\mathrm{pH} 7$-but kinetically inefficient. However, the presence of iron chelates under certain pathological conditions can enhance $\mathrm{H}_{2} \mathrm{O}_{2}$ efficiency through Haber-Weiss-like reactions (see Equations (1)-(3)) [145]:

$$
\begin{aligned}
& \mathrm{Fe}^{3+}+\mathrm{H}_{2} \mathrm{O}_{2} \longrightarrow \mathrm{Fe}^{2+}+\mathrm{O}_{2}^{-\bullet}+2 \mathrm{H}^{+} \\
& \mathrm{Fe}^{2+}+\mathrm{H}_{2} \mathrm{O}_{2} \longrightarrow \mathrm{Fe}^{3+}+\mathrm{HO}^{-}+\mathrm{HO}^{\bullet} \text { (Fenton's reaction) } \\
& \mathrm{O}_{2}^{-\bullet}+\mathrm{Fe}^{3+} \longrightarrow \mathrm{Fe}^{2+}+\mathrm{O}_{2}
\end{aligned}
$$

The hydroxyl radical product is highly reactive, sequestering hydrogen atoms from available substrates. The resulting carbon-centered radicals may react with molecular oxygen to generate (hydro-) peroxides (Equations (4)-(6)):

$$
\begin{gathered}
\mathrm{HO}^{\bullet}+\mathrm{RH} \longrightarrow \mathrm{H}_{2} \mathrm{O}+\mathrm{R}^{\bullet} \\
\mathrm{R}^{\bullet}+\mathrm{O}_{2} \longrightarrow \mathrm{RO}_{2}^{\bullet} \\
\mathrm{RO}_{2}^{\bullet}+\mathrm{H}^{+}+\mathrm{Fe}^{2+} \longrightarrow \mathrm{ROOH}+\mathrm{Fe}^{3+}
\end{gathered}
$$

Nevertheless, homeostatic cells exert a tight control over metal chelation to avoid Fenton's reactions. Indeed, a set of antioxidant agents prevent a surge in the levels of ROS. Hence, except for pathological conditions, $\mathrm{H}_{2} \mathrm{O}_{2}$ requires the activity of peroxidases to function efficiently as an oxidant. Within the IMM, Cc displays both peroxidase and oxygenase activities, the latter promoting CL oxidation, while sparing other phospholipids $[18,146]$. This event is crucial for the release of mitochondrial proapoptotic factors into the cytoplasm [18].

5.1. Peroxidase and Oxygenase Activities of Cytochrome c (Dr. Jeckyll and Mr. Hyde). Heme peroxidases constitute a vital and ubiquitous group of heme enzymes catalyzing the twoelectron oxidation of substrates using $\mathrm{H}_{2} \mathrm{O}_{2}$ as the ultimate electron acceptor [147, 148]. In canonical peroxidases, $\mathrm{H}_{2} \mathrm{O}_{2}$ is added to the pentacoordinated, high-spin Fe $\mathrm{F}^{\mathrm{III}}$. The resulting state-Compound $\mathrm{I}-$ is two oxidation equivalents above the resting state and is reduced back to the resting configuration in two steps through Compound II. Both states, Compounds I and II, are high valence oxoferryl $\left(\mathrm{Fe}^{\mathrm{IV}}\right)$ derivatives, but the first comprises an additional $\pi$-cation radical (see Equations (7)-(9)) (Figure 4) [147].

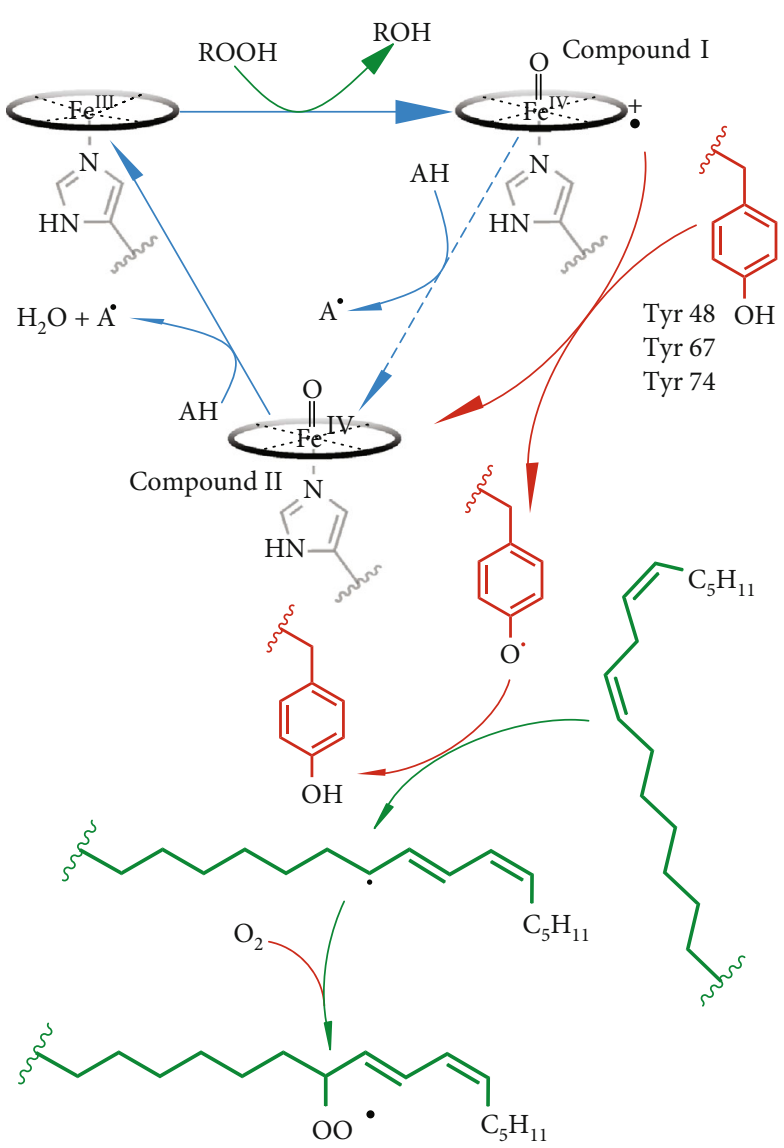

FIgURe 4: Peroxidase and oxygenase activities of cytochrome $c$. Reaction model merging the proposal from Kagan and collaborators [149] and the adapted catalytic model of cyclooxygenases as reviewed by Marnett [150]. Blue arrows correspond to the canonical peroxidase cycle [146]. Heterolytic cleavage of a peroxide substrate-preferentially for $\mathrm{C} c$, a lipid hydroperoxide-yields the corresponding hydroxyl derivative (or water when the substrate is $\mathrm{H}_{2} \mathrm{O}_{2}$ ) and Compound $\mathrm{I}$, which is reduced back to the resting ferric state in two sequential singleelectron transfers from A substrate. Red and green arrows indicate the reactions purportedly leading to oxygenase activity according to the literature. Spin trap experiments have detected Y48 radicals [151]. Dimers of tyrosines 67 and 74 and oxidation products of $\mathrm{Y} 48$ are detectable even in the absence of $\mathrm{H}_{2} \mathrm{O}_{2}$ [152]. The tyrosyl radical sequesters a hydrogen atom from an unsaturated fatty acid. Finally, $\mathrm{O}_{2}$ reacts with the alkyl radical to form an alkyl peroxide radical as an initial product undergoing further reactions.

Heme $\left[\mathrm{Fe}^{\mathrm{III}}\right]_{\mathrm{RS}}+\mathrm{H}_{2} \mathrm{O}_{2} \longrightarrow \mathrm{Heme}\left[\mathrm{O}=\mathrm{Fe}^{\mathrm{IV}}-\mathrm{R}^{\bullet+}\right]_{\mathrm{CompI}}+\mathrm{H}_{2} \mathrm{O}$

$$
\begin{aligned}
\text { Heme }[\mathrm{O}= & \left.\mathrm{Fe}^{\mathrm{IV}}-\mathrm{R}^{\bullet+}\right]_{\text {CompI }} \\
& +\mathrm{AH}_{2} \longrightarrow \text { Heme }\left[\mathrm{O}=\mathrm{Fe}^{\mathrm{IV}}\right]_{\mathrm{CompII}}+\mathrm{AH}^{\bullet} \\
\text { Heme }[\mathrm{O}= & \left.\left.\mathrm{Fe}^{\mathrm{IV}}\right]_{\mathrm{CompII}}+\mathrm{AH}_{2} \longrightarrow \mathrm{Heme}_{\mathrm{Fe}}{ }^{\mathrm{III}}\right]_{\mathrm{RS}} \\
& +\mathrm{AH}^{\bullet \bullet}+\mathrm{H}_{2} \mathrm{O}
\end{aligned}
$$


In true peroxidases, a histidine residue acts as an acidbase catalyst at the distal side of the heme ring, while a highly conserved arginine residue stabilizes the alkoholate leaving group to favor the heterolytic cleavage of the peroxide $\mathrm{O}-\mathrm{O}$ bond [153]. The orientation of these residues and the hydrogen-bond network at the heme distal side are critical for efficient formation of Compound I [154]. As recently pointed out by Vlasova [148], the composition of a true peroxidase active site prevents its damage by highly oxidizing intermediate compounds.

$\mathrm{C} c$ and other hemeproteins can act as pseudoperoxidases; that is, under only certain stimuli they show peroxidase activity $[148,155]$. Contrary to true peroxidases, the surroundings of heme moiety are unprotected against oxidation, so the peroxidase activity ends up damaging the protein. In the early 1990s, Radi and collaborators reported the ability of $\mathrm{Cc}$ to oxidize small compounds in solution [145] and to carry out lipid peroxidation [146] in the presence of $\mathrm{H}_{2} \mathrm{O}_{2}$. Nevertheless, the reactivity of $\mathrm{C} c$ towards $\mathrm{H}_{2} \mathrm{O}_{2}$ was low, as it requires the absence of the sixth ligand. Thus, the $K_{\mathrm{m}}$ value for $\mathrm{H}_{2} \mathrm{O}_{2}$ was very high-ca. $65 \mathrm{mM}$. In this sense, oxidative reactions showed a time lag after the addition of $\mathrm{H}_{2} \mathrm{O}_{2}$, indicative of an activation step. Moreover, peroxidase activity in solution decayed at $\mathrm{pH}$ values higher than 8 [145]. Poor reactivity may also result from the absence of histidine at the distal site (vide infra), as it is an acid-base residue "pumping" the heterolytic cleavage of $\mathrm{H}_{2} \mathrm{O}_{2}$ during Compound I formation. Based on chemiluminescence analyses of the reaction, Chance and coworkers proposed a homolytic reaction mechanism (Equations (10)-(12)) [156], supported by EPR spin trap studies of small organic hydroperoxides [157].

$$
\begin{gathered}
\text { Heme }\left[\mathrm{Fe}^{\mathrm{III}}\right]+\mathrm{H}_{2} \mathrm{O}_{2} \longrightarrow \text { Heme }\left[\mathrm{HO}^{\bullet}-\mathrm{Fe}^{\mathrm{III}}\right] \\
\mathrm{HO}^{\bullet}+\mathrm{H}_{2} \mathrm{O}_{2} \longrightarrow \mathrm{H}_{2} \mathrm{O}+\mathrm{HO}_{2}^{\bullet}
\end{gathered}
$$

Heme $\left[\mathrm{HO}^{\bullet}-\mathrm{Fe}^{\mathrm{III}}\right]+\mathrm{HO}_{2}^{\bullet} \longrightarrow$ Heme $\left[\mathrm{Fe}^{\mathrm{III}}\right]+\mathrm{O}_{2}+\mathrm{H}_{2} \mathrm{O}$

However, EPR spin trap experiments highlighted the generation of $\mathrm{C} c$ tyrosine radicals upon treatment with $\mathrm{H}_{2} \mathrm{O}_{2}[18,151,155,158]$. Furthermore, spin trap experiments detecting radical products resulting from oxidation of different substrates by $\mathrm{H}_{2} \mathrm{O}_{2}$ strongly suggested the reaction being mediated by an oxoferryl $\left[\mathrm{O}=\mathrm{Fe}^{\mathrm{IV}}\right]$ intermediate [155]. Analysis of the orientation of this radical within the native state identified a tyrosine residue at the $\Omega_{\mathrm{II}}$-loop-namely, Y48 in horse heart $\mathrm{C} c$ and either Y46 or Y48 in human $\mathrm{C} c$ [159]. The peroxidase activity of $\mathrm{C} c$ in the presence of CL increases by three orders of magnitude when the driving oxidant is a lipid peroxide instead of $\mathrm{H}_{2} \mathrm{O}_{2}$ [149]. Spin trap analysis of reaction products by Kagan and collaborators indicates a diversity of catalytic mechanisms depending on the binding site of the substrate, namely, a homolytic peroxide cleavage minority mechanism and a major, heterolytic mechanism. Notably, the small hydroperoxide substrates involved in this pathway dock near R38 and H33. However, how the docked structure undergoes conformational changes to fulfil all geometrical constraints needed for Compound I formation remains unclear (Figure 4).

Binding of hydrogen peroxide to the heme iron is a key step in the reaction mechanism underlying peroxidase activity. The reactive species need to displace the thioether axial ligand. This takes place when a strong interaction between $\mathrm{Cc}$ and a membrane induce a substantial conformational change in the hemeprotein $[15,84,93,95-97,109,111]$. Nevertheless, Kagan and coworkers also detected peroxidase activity in $\mathrm{Cc}$ at low $\mathrm{CL} / \mathrm{Cc}$ ratios-at which the most interactions are weak electrostatic [15]. Furthermore, they found that the energy required to activate peroxidase activity is lower than that required for partial unfolding of the protein. In fact, as pointed out before, the bond joining iron to the thioether ligand is quite weak [160]. Thus, "breathing" fluctuations of $\Omega_{\mathrm{II}}$ and $\Omega_{\mathrm{III}}$-loops may facilitate the replacement of the thioether ligand by small reactants-such as cyanide, carbon monoxide, water, or hydrogen peroxide-without demanding major structural changes. In fact, $\mathrm{C} c$ peroxidase activity rises in the presence of $\mathrm{H}_{2} \mathrm{O}_{2}$ as the concentration of denaturant increases, as previously observed in a similar analysis with bacterial cytochrome $c_{550}$ [161]. Statistical analysis of activity and unfolding slopes indicate that increasing the motions of the weakest $\Omega$-loops correlates well with peroxidase activity in the "compact" $\mathrm{C} c$ species [162].

The peroxidase activity of $\mathrm{C} c$ can exert a protective role in mitochondria under certain conditions [11]. Indeed, reduction of lipoid hydroperoxide compounds to hydroxyl ones provides a way of relieving oxidative stress in the mitochondrial membrane while generating signaling molecules [149]. Moreover, $\mathrm{O}_{2}{ }^{-\bullet}$ reduces nitric oxide ( $\left.{ }^{\circ} \mathrm{NO}\right)$ generated in mitochondria under stress to form peroxynitrite (HOONO), a highly reactive species. $\mathrm{C} c$-CL complexes have been proposed to aid peroxynitrite detoxification to yield either nitrate or nitrite through an oxoferryl state [163].

Conversely, the peroxidase activity of $\mathrm{C} c$ has been implicated in certain pathologies. For instance, oxidation of sulfite to its radical $\mathrm{SO}_{3}{ }^{-\bullet}$ is a key mechanism in sulfite toxicity [164]. Moreover, $\mathrm{Cc}$ mediates the formation of tyrosine radicals responsible for $\alpha$-synuclein dimerization [66, 165], which leads to the development of the Lewy body diseases.

Canonical peroxidase activity involves two sequential one-electron oxidation steps and no transfer of oxygen from the oxoferryl complexes to the substrate [146]. Nevertheless, Compound I in certain heme enzymes-such as cytochrome P450-can transfer oxygen to certain substrates yielding hydroxy-derivatives. Interestingly, hydroxy-derivatives of CL cannot undergo peroxidation and inhibit the release of Cc [166]. Altogether, considering the findings above concerning tyrosyl radicals in Cc [151], Kagan and collaborators proposed that $\mathrm{C} c$ acts as an oxygenase to produce CL peroxidation [167]. This activity would also be responsible for phosphatidylserine peroxidation affecting the plasma membrane during apoptosis [65]. This hypothesis suggests that hydrogen is transferred to Compound I from a nearby tyrosine residue to yield oxoferryl Compound II and the aforementioned tyrosyl radical (Figure 4). This mechanism is similar to that proposed for cyclooxygenases, in which a hydrogen atom is sequestered from an acyl chain, generating 
a carbon-centered radical capable of reacting with molecular oxygen [150].

Unlike true peroxidases, the environment of the heme moiety is unprotected from highly oxidizing species arising during the catalytic cycle [148]. When reacting with $\mathrm{H}_{2} \mathrm{O}_{2}$, degradation of the heme porphyrin often becomes apparent by a diminution of the Soret band intensity [146, 156]. A thorough mass spectrometry analysis of $\mathrm{C} c$ residue adducts derived from $\mathrm{H}_{2} \mathrm{O}_{2}$ has been carried out by Flemmig and collaborators [152]. Several oxidation reactions can occur to produce a methyl-sulfoxide derivative from the methionine thioether, a sulfonic acid derivative from cysteines and 2-oxohistidine from histidine. While tyrosine residues can covalently cross-link or undergo oxidation to dihydroxyphenylalanine (DOPA) and subsequently to quinones, lysine residues can undergo carbonylation $[152,168$, 169]. These changes occur when $\mathrm{H}_{2} \mathrm{O}_{2}$ is added to $\mathrm{Cc}$ samples [80, 152, 170-173].

Remarkably, different regions in the protein display different sensitivities to oxidation depending on the environment. For instance, specific M80 oxidation takes place in the presence of DOPC/DOPE micelles [174]. The $\Omega_{\mathrm{III}}$-loop is the first to be affected, whereas foldon I (helices I and IV) is the least affected by oxidation. Notably, the peroxidase activity of $\mathrm{C} c$ increases in a time-dependent manner upon the addition of $\mathrm{H}_{2} \mathrm{O}_{2}$. Such increments in peroxidase activity may result from successive oxidation of M80 and lysine residues, as proposed by Yin and Konermann [80, 170]. Indeed, M80 oxidation promotes conformation exchange in $\mathrm{Cc}$ which impacts on heme ligation. With time, oxidative damage extends to the porphyrin ring, releasing iron capable of performing Fenton's reactions [173]. Finally, it is worth noting that CL peroxides can induce at least some of these oxidative PTM [152].

5.2. The Alkaline Transition of Cytochrome $c$ and Peroxidase Activity. As mentioned above, previous data obtained using monoclonal antibodies highlighted that an alkaline-like conformation could interact with CL and exit mitochondria during apoptosis [106]. These antibodies also recognize the M80A mutant in the cell nucleus [175]. Notably, this mutant displays enhanced peroxidase activity. In addition, the peroxidase activity of $\mathrm{Cc}$ is somewhat $\mathrm{pH}$ dependent $[145,176]$. Indeed, for horse heart $\mathrm{C} c$, peroxidase activity increases at acidic $\mathrm{pH}$ values [177] and slows beyond $\mathrm{pH}$ 8 [145]. Furthermore, the ability of $\mathrm{C} c$ to oxidize $\mathrm{O}_{2}{ }^{-\bullet}$ falls at $\mathrm{pH}$ values above 7 [7]. The affinity of $\mathrm{Cc}$ towards membranes and the interaction patch involved also depend on $\mathrm{pH}[15,98,120,127]$. These effects illustrate how $\mathrm{pH}-$ dependent conformation changes modulate the different activities performed by $\mathrm{C} c$.

A number of mutations and PTM have been reported to simultaneously affect the peroxidase activity of $\mathrm{C} c$ while bringing the so-called alkaline transition to lower even physiological $\mathrm{pH}$ values [178-182]. Loss of M80 coordination is evident from NMR spectra and UV-Vis spectra in all these studies. $\mathrm{C} c$ peroxidase activity requires the heme iron to be pentacoordinated; the relationship with the $\mathrm{p} K_{\mathrm{A}}$ of the alkaline transition could be attributable to the lysine amine being weaker than methionine thioether in the ligand. However, at a neutral $\mathrm{pH}$, lysine is a stronger ligand than methionine [183]. In fact, horse heart and human $\mathrm{C} c$ show lower peroxidase activities at alkaline $\mathrm{pH}$ values $[145,182]$. Moreover, mutation $\mathrm{M} 100 \mathrm{~K}$ in $P$. versutus cytochrome $c_{550}$ makes the protein more stable at neutral $\mathrm{pH}$ while decreasing its peroxidase activity 20 -fold [183].

Nevertheless, the shift in the alkaline transition towards lower $\mathrm{pH}$ values indicates destabilization or higher dynamics in the $\Omega_{\mathrm{II}^{-}}$and $\Omega_{\mathrm{III}}$-loops in the Met-coordinated species. Given the weakness of the thioether ligand bond towards iron, increasing fluctuations of these loops will increase the population of high-spin species and/or alternative low-spin (e.g., bis-His) species below the $\mathrm{p} K_{\mathrm{A}}$ value of the transition. This is observable in phosphomimic mutants, as well as in nitrated species of Cc [178-180, 184-186]. Furthermore, enhanced dynamics facilitate the access of small substrates to the heme iron [162].

5.3. Control of Cardiolipin Oxidation by Post-translational Modification of Cytochrome $c$. Protein PTM regulate tightly controlled cellular processes and increase the functional diversity of proteins, often acting as a cell response switch. Several post-translational modifications modulate $\mathrm{C} c$ structure and functionality, such as sulfoxidation [187], carbonylation [152], homocysteinylation [188], nitration [179, 180], and phosphorylation [189] (Figure 5). Phosphorylation of tyrosine residues is associated with many human pathologies including cancer, ischemia, asthma, and sepsis. As highlighted earlier, tyrosine radicals are key for the oxygenase activity of $\mathrm{C} c$ [157]. Thus, the amount of hydroxyl products from TOCL oxidation is lower when Y48E phosphomimic species instead of $\mathrm{WT} \mathrm{Cc}$ acts as a catalyst [190]. Additionally, tyrosine phosphorylation impairs the formation of radicals, preventing dimerization [191]. This fact may be critical in pathological processes such as Parkinson's disease [66]. Therefore, the PTM that affect these residues are key in regulating $\mathrm{C} c$ activity.

Given the difficulty in preserving the phosphorylation state of $\mathrm{Cc}$ outside of cell extracts, a common strategy to investigate consequences of phosphorylation is to mimic the modification by site-directed mutagenesis. All phosphomimetic $\mathrm{C} c$ species, except a mutant at position 97, display altered affinity towards cardiolipin $[178,186,190$, 192-195]. The peroxidase activity of both free $\mathrm{Cc}$ and $\mathrm{Cc}$-CL complexes increases in the phosphomimetic T28D and Y $48 p$ CMF. However, for the Y48E species, the increase only occurs with the free protein (Table 1) $[178,190,192$, 194]. In addition, at a high CL/lipid ratio, the peroxidase activity of the T28E mutant decreases [195]. A possible explanation may be that the greater population of CL versus other lipids in the liposome composition promote unfolding of the hemeprotein, acting as an off switch (Table 1) [131]. Hence, the negative charge at these positions could induce structural changes in the heme crevice which allow greater accessibility for hydrogen peroxide (Figure 5).

Peroxynitrite generated during nitrooxidative stress is a powerful amino acid modifier, affecting tyrosine residues among others [201]. Common products of the reaction 


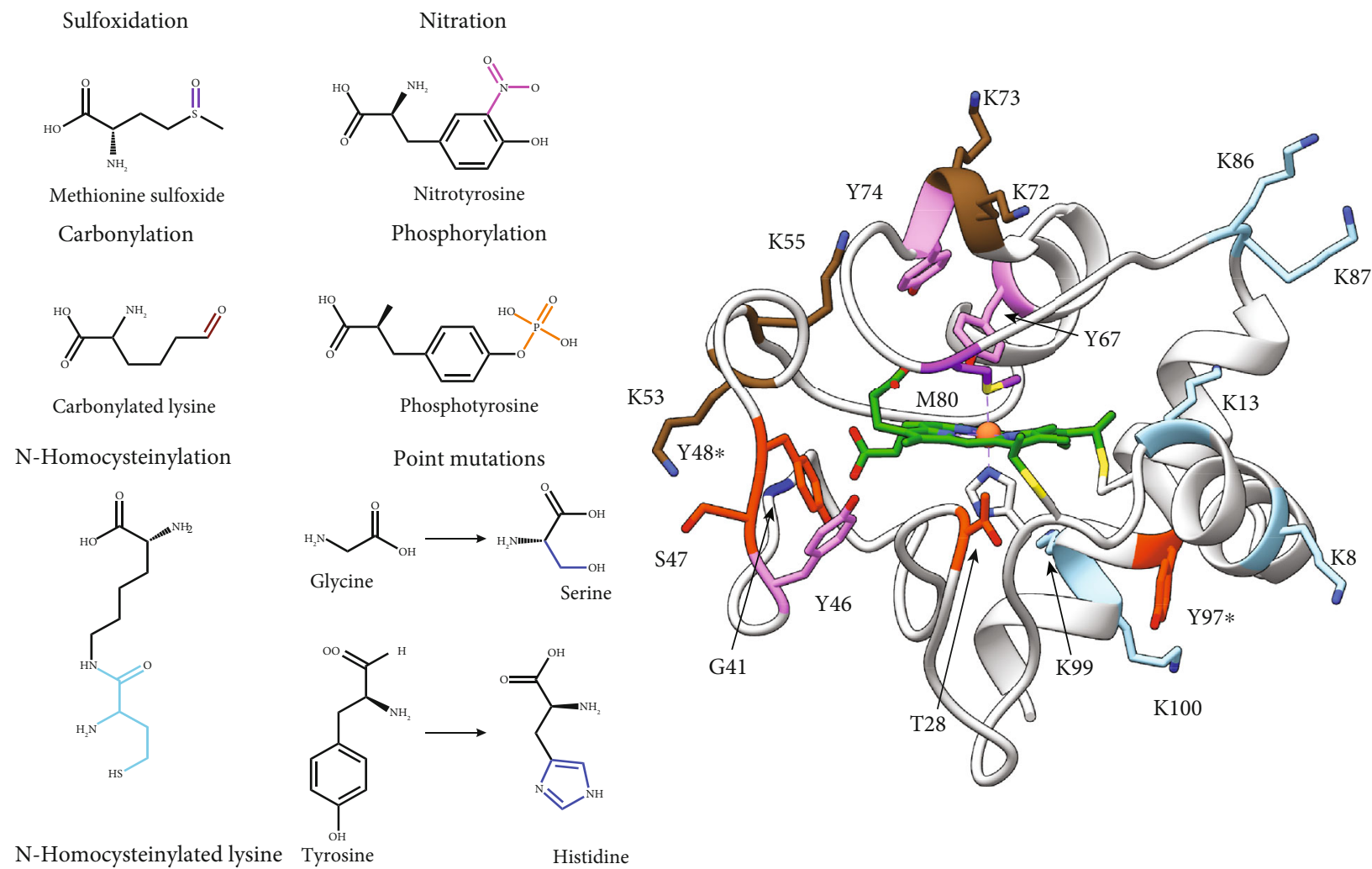

FIgURE 5: Functional implications of PTM and mutations of cytochrome $c$. Left: chemical modifications of cytochrome $c$ residues. Right: ribbon representation of oxidized human $\mathrm{Cc}$ (PDB 2N9J) [92]. Residues are colored by type of PTM: pink for nitration, purple for sulfoxidation, orange for phosphorylation, brown for carbonylation, cyan for N-homocysteinylation, and blue for point mutations. Y48 (asterisk) can be either phosphorylated, nitrated, or mutated for histidine, while Y97 (asterisk) can be phosphorylated or nitrated.

between tyrosine and HOONO are 3,5-dinitrotyrosine, 3nitrotyrosine, tyrosine radicals, and dityrosine. Nevertheless, treatment of $\mathrm{C} c$ in vitro with peroxynitrite yields its 3 -nitrotyrosine adducts, with the nitro group attaching to one of the $\mathrm{C}_{\varepsilon}$ of the aromatic ring [202]. Nitration affects the redox potential of $\mathrm{C} c$ as well as its electron-exchange kinetics, depending on the residue involved [203]. The nitration of Y46, Y48, Y74, and Y97 residues also increases the peroxidase activity of $\mathrm{C} c$ and lowers the $\mathrm{p} K_{\mathrm{A}}$ value of the alkaline transition besides other functional properties [179, 180, 183, 185, 197, 204, 205] (Table 1). Nitration of $\mathrm{Cc}$ has been associated with several diseases, including chronic nephropathy [206].

All modifications/mutations of S47 and Y67 alter the peroxidase activity of $C c[79,179,185,192,195,197]$. Y67 is located close to Met 80 and is part of the hydrophobic pocket which houses the acyl chains of CL. This residue is also key for the stability of the $\Omega_{\mathrm{III}}-$ loop (Table 1 ).

Homocysteinylation is a PTM that involves the covalent bonding of a homocysteine thiolactone-an intermediate metabolite of methionine metabolism - with a lysine residue [188]. Upregulation of this PTM is implicated in several human pathologies including cancer and cardiopathies $[198,207]$. The degree of homocysteinylation, as well as the rate at which this modification occurs in the presence of homocysteine thiolactone, is related to the number of lysine residues [188]. Human Cc displays a lysine content of $17.1 \%$ in its amino acid composition, which makes it sensitive to homocysteinylation. Homocysteinylation of surface lysines on $\mathrm{Cc}$ causes aggregation of the protein. However, $\mathrm{N}$-homocysteinylated lysines adjacent to the heme cavity produce conformational changes, disrupt the coordination of the M80 axial ligand, and alter the redox state of $\mathrm{C} c$, reducing the iron of the heme group $[196,208]$. These conformational changes increase $\mathrm{C} c$ peroxidase activity (Table 1) [209].

As discussed before, $\mathrm{C} c$ is modulated by several oxidative modifications due to its activity, eventually leading to changes in iron coordination. One oxidative modification is the carbonylation of lysine residues, which affects residues 72 and 73, both of which are involved in the alkaline transition of Cc [170] (Figure 5). Reportedly, successive carbonylation events at $\mathrm{K} 53, \mathrm{~K} 55, \mathrm{~K} 72$, and $\mathrm{K} 73$ lead to the formation of the pentacoordinated $\mathrm{C} c$ species, resulting in increased $\mathrm{C} c$ peroxidase activity (Table 1) [170]. Similarly, the sulfoxidation of M80 facilitates the formation of a Compound I-type intermediate that initiates the activity of $\mathrm{Cc}$ peroxidase (Table 1) [171, 210].

5.4. Peroxidase Activity of Cytochrome $c$ and Diseases. Since the peroxidase activity of $\mathrm{Cc}$ relates to the activation of apoptosis, it is a clear target for the development of more efficient 
TABLE 1: Effect of PTM and point mutations on cytochrome $c$ peroxidase activity.

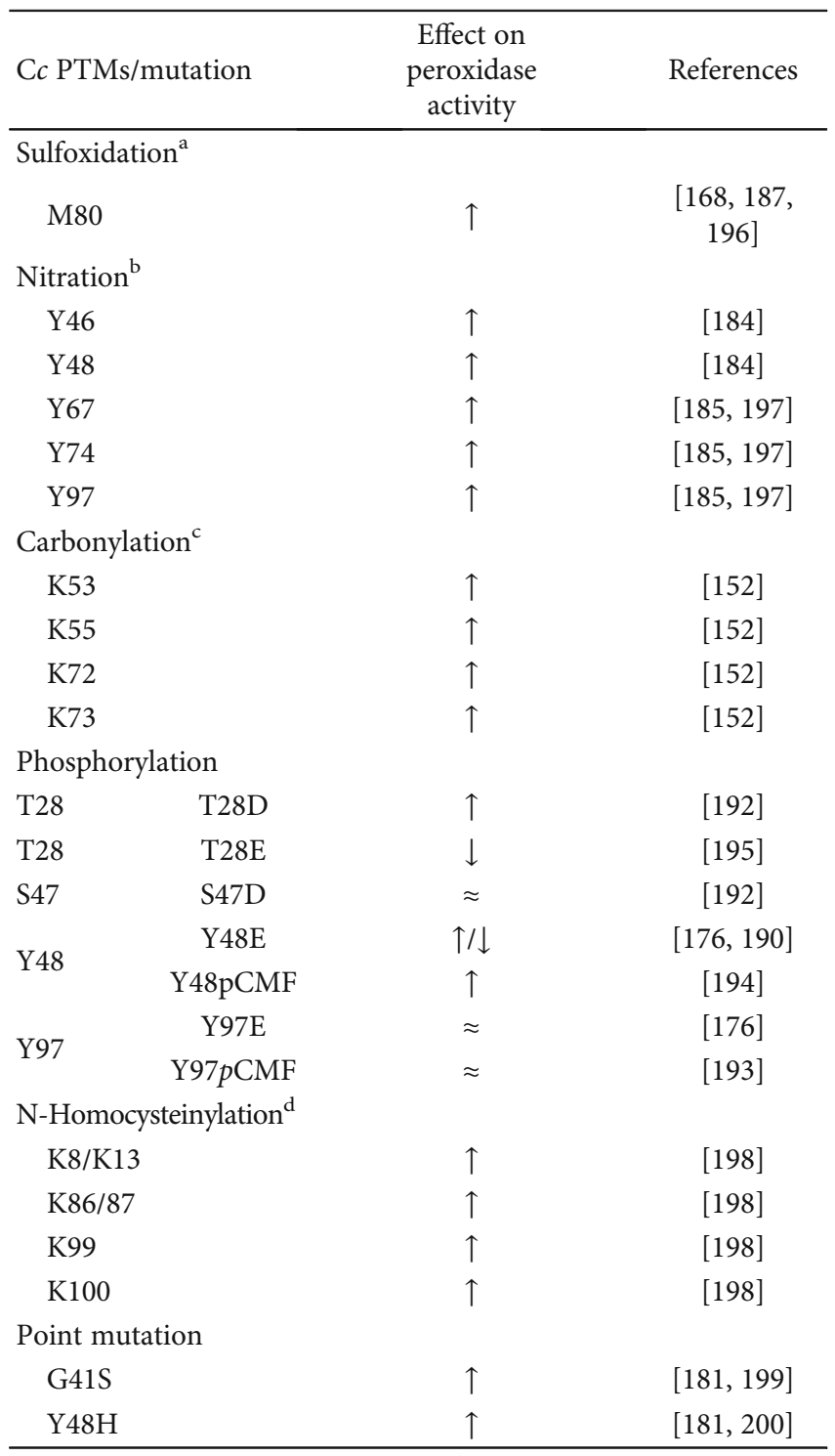

${ }^{\mathrm{a}}$ Determined under oxidative stress. ${ }^{\mathrm{b}}$ Determined after peroxynitrite treatment. ${ }^{\mathrm{c}}$ Determined after chloramine- $\mathrm{T}$ treatment. ${ }^{\mathrm{d}}$ Determined after homocysteine thiolactone treatment.

therapies against certain diseases or pathologies. There are several examples in the literature that shed light on this topic.

The point mutations $\mathrm{Y} 48 \mathrm{H}$ and G41S in $\mathrm{Cc}$ cause the appearance of a special type of thrombocytopenia (thrombocytopenia 4) which is an asymptomatic disorder [199, 200]. Thrombocytopenia 4 is notable for normal platelet production. However, in thrombocytopenia platelets are not transported to the bone marrow and remain in the matrix, causing the effective platelet content to be lower. Both mutations cause an increase in peroxidase activity, which is related to an increase in the population of $\mathrm{C} c$ in the pentacoordinated heme state $[181,211,212]$ (Table 1).

Most neurodegenerative diseases are associated with cellular stress and apoptotic processes. Due to the double role played by $\mathrm{C} c$ in the electron transport chain and apoptosis, it represents an amenable target for the development of therapies against neurodegenerative pathologies. For example, post-translational phosphorylation of $\mathrm{Cc}$ at Y97 is an excellent neuroprotective strategy following brain injury as it increases the efficiency of electron transport during hypoxic conditions [193, 213]. Moreover, $\mathrm{C} c$ has been implicated in the development of Parkinson's disease-as it colocalizes with $\alpha$-synuclein in the Lewy bodies [214]. In fact, the peroxidase activity of $\mathrm{C} c$ plays an important role in the aggregation of $\alpha$-synuclein by tyrosine dimerization $[66,174]$.

Minocycline is an antibiotic functional against both Gram-positive and Gram-negative bacteria. Additionally, it displays neuroprotective properties [215]. The antibiotic minocycline impairs the interaction between $\mathrm{C} c$ and $\mathrm{CL}$, inhibiting the activation of peroxidase activity and the consequent release of $\mathrm{Cc}$ into the cytosol to trigger apoptosis [216-218].

Nitric oxide is a well-known inhibitor of $\mathrm{C} c$ peroxidase activity and thus may downregulate apoptosis [219, 220]. Flavonoids are excellent antioxidants that prevent cellular aging by ROS scavenger activity. In addition, they can inhibit Cc peroxidase activity, preventing proapoptotic events [221].

The protection of healthy cells during radiotherapy is a hot topic. In fact, novel synthetic compounds-e.g., imidazole-substituted fatty acids-are currently being trialed in order to preserve healthy cells by inhibiting the peroxidase activity of $\mathrm{C} c$ during the irradiation process [222, 223]. These de novo compounds, mainly imidazole conjugates, block access to the heme crevice preventing the activation of peroxidase activity.

Finally, the activation of proapoptotic events, such as the release of $\mathrm{C} c$ after the peroxidation of $\mathrm{CL}$, may be a good target for the development of more efficient and specific therapies against cancer [224, 225].

\section{Concluding Remarks}

In this review, we have outlined major advances and hypotheses regarding the oxidation of CL by Cc. CL oxidation is a crucial event at the onset of a diverse range of pathologies, and thus, controlling it has become a key objective of current research. Targeting $\mathrm{C} c$-a key player in CL oxidation-has emerged as an important task.

Since its discovery last century, $\mathrm{C} c$ has displayed great functional complexity despite its apparently simple structure. Indeed, its highly dynamic architecture, which enables conformation changes critical in regulating metabolism, signaling, and cell fate, still amazes the scientific community. $\mathrm{Cc}$ interacts with membranes in different ways depending on their composition and curvature, being able of modifying the latter. When the hemeprotein interacts with lipids, it may undergo subtle changes in the dynamics of its most flexible foldons or may even unfold. A plethora of factors, including PTM, control these phenomena.

The chemical activity of this protein ranges from the simplest reactions to diverse and complex reaction mechanisms to drive the oxidation of substrates including CL. In the recent years, we have witnessed concerted effort to unveil the intimate chemistry of this process. Solving this 
conundrum will require us to discriminate minority conformations in functional assays and elucidate how this activity is tuned under distinct conditions. Nevertheless, knowledge has already amassed on the subject enabling us to examine the inhibition of CL oxidation, which will aid the development of translational approaches.

\section{Conflicts of Interest}

The authors declare that there is no conflict of interest regarding the publication of this review article.

\section{Acknowledgments}

This work was supported by the Ministry of Science and Innovation/FEDER-National Research Agency (PGC2018096049-B-I00), European Social Fund, Andalusian Government (BIO-198, US-1257019, and US-1254317), and TA Instruments. G.P.M. was awarded a PhD fellowship from the Spanish Ministry of Education, Culture and Sport (FPU17/04604). Molecular graphics and analyses were performed with the UCSF Chimera software, developed by the Resource for Biocomputing, Visualization and Informatics at the University of California, San Francisco, with support from NIH (P41-GM103311).

\section{References}

[1] Y. M. Lee, "Mitochondrial diseases," Journal of Epilepsy Research, vol. 2, no. 1, pp. 1-4, 2012.

[2] J. F. Turrens, "Mitochondrial formation of reactive oxygen species," The Journal of Physiology, vol. 552, no. 2, pp. 335344, 2003.

[3] Y. Y. Tyurina, C. M. St Croix, S. C. Watkins et al., "Redox (phospho)lipidomics of signaling in inflammation and programmed cell death," Journal of Leukocyte Biology, vol. 106, no. 1, pp. 57-81, 2019.

[4] N. Kajarabille and G. O. Latunde-Dada, "Programmed celldeath by ferroptosis: antioxidants as mitigators," International Journal of Molecular Sciences, vol. 20, no. 19, p. 4968, 2019.

[5] V. E. Kagan, Y. Y. Tyurina, W. Y. Sun et al., "Redox phospholipidomics of enzymatically generated oxygenated phospholipids as specific signals of programmed cell death," Free Radical Biology and Medicine, vol. 147, pp. 231-241, 2020.

[6] J. Dudek, "Role of cardiolipin in mitochondrial signaling pathways," Frontiers in Cell and Developmental Biology, vol. 5, p. 90, 2017.

[7] J. Butler, G. G. Jayson, and A. J. Swallow, "The reaction between the superoxide anion radical and cytochrome c," Biochimica et Biophysica Acta (BBA) - Bioenergetics, vol. 408, no. 3, pp. 215-222, 1975.

[8] A. Atlante, P. Calissano, A. Bobba, A. Azzariti, E. Marra, and S. Passarella, "Cytochrome $c$ is released from mitochondria in a reactive oxygen species (ROS)-dependent fashion and can operate as a ROS scavenger and as a respiratory substrate in cerebellar neurons undergoing excitotoxic death," Journal of Biological Chemistry, vol. 275, no. 47, pp. 37159-37166, 2000.
[9] M. O. Pereverzev, T. V. Vygodina, A. A. Konstantinov, and V. P. Skulachev, "Cytochrome c, an ideal antioxidant," Biochemical Society Transactions, vol. 31, no. 6, pp. 1312-1315, 2003.

[10] P. Pasdois, J. E. Parker, E. J. Griffiths, and A. P. Halestrap, "The role of oxidized cytochrome $\mathrm{c}$ in regulating mitochondrial reactive oxygen species production and its perturbation in ischaemia," Biochemical Journal, vol. 436, no. 2, pp. 493505, 2011.

[11] E. Sedlak, M. Fabian, N. C. Robinson, and A. Musatov, "Ferricytochrome c protects mitochondrial cytochrome c oxidase against hydrogen peroxide-induced oxidative damage," Free Radical Biology and Medicine, vol. 49, no. 10, pp. 15741581, 2010.

[12] S. S. Korshunov, B. F. Krasnikov, M. O. Pereverzev, and V. P. Skulachev, "The antioxidant functions of cytochromec," FEBS Letters, vol. 462, no. 1-2, pp. 192-198, 1999.

[13] V. A. Tyurin, Y. Y. Tyurina, A. N. Osipov et al., "Interactions of cardiolipin and lyso-cardiolipins with cytochrome $c$ and tBid: conflict or assistance in apoptosis," Cell Death \& Differentiation, vol. 14, no. 4, pp. 872-875, 2007.

[14] M. Huttemann, P. Pecina, M. Rainbolt et al., "The multiple functions of cytochrome $c$ and their regulation in life and death decisions of the mammalian cell: from respiration to apoptosis," Mitochondrion, vol. 11, no. 3, pp. 369-381, 2011.

[15] N. A. Belikova, Y. A. Vladimirov, A. N. Osipov et al., "Peroxidase activity and structural transitions of cytochrome $\mathrm{C}$ bound to cardiolipin-containing membranes," Biochemistry, vol. 45, no. 15, pp. 4998-5009, 2006.

[16] Y. Shidoji, K. Hayashi, S. Komura, N. Ohishi, and K. Yagi, "Loss of molecular interaction between cytochrome $\mathrm{c}$ and cardiolipin due to lipid peroxidation," Biochemical and Biophysical Research Communications, vol. 264, no. 2, pp. 343347, 1999.

[17] G. Petrosillo, F. M. Ruggiero, and G. Paradies, "Role of reactive oxygen species and cardiolipin in the release of cytochrome c from mitochondria," The FASEB Journal, vol. 17, no. 15, pp. 2202-2208, 2003.

[18] V. E. Kagan, V. A. Tyurin, J. Jiang et al., "Cytochrome $c$ acts as a cardiolipin oxygenase required for release of proapoptotic factors," Nature Chemical Biology, vol. 1, no. 4, pp. 223232,2005

[19] Y. Y. Tyurina, S. M. Poloyac, V. A. Tyurin et al., "A mitochondrial pathway for biosynthesis of lipid mediators," Nature Chemistry, vol. 6, no. 6, pp. 542-552, 2014.

[20] M. Schlame, "Thematic review series: glycerolipids. Cardiolipin synthesis for the assembly of bacterial and mitochondrial membranes," Journal of Lipid Research, vol. 49, no. 8, pp. 1607-1620, 2008.

[21] G. L. Powell and J. Jacobus, "nonequivalence of the phosphorus atoms in cardiolipin," Biochemistry, vol. 13, no. 19, pp. 4024-4026, 1974.

[22] M. Schlame, M. Ren, Y. Xu, M. L. Greenberg, and I. Haller, "Molecular symmetry in mitochondrial cardiolipins," Chemistry and Physics of Lipids, vol. 138, no. 1-2, pp. 38-49, 2005.

[23] M. Kates, J. Y. Syz, D. Gosser, and T. H. Haines, "pH-dissociation characteristics of cardiolipin and its $2^{\prime}$-deoxy analogue," Lipids, vol. 28, no. 10, pp. 877-882, 1993.

[24] J. Pan, X. Cheng, M. Sharp, C. S. Ho, N. Khadka, and J. Katsaras, "Structural and mechanical properties of cardiolipin lipid bilayers determined using neutron spin echo, small 
angle neutron and X-ray scattering, and molecular dynamics simulations," Soft Matter, vol. 11, no. 1, pp. 130-138, 2015.

[25] W. Hübner, H. H. Mantsch, and M. Kates, "Intramolecular hydrogen bonding in cardiolipin," Biochimica et Biophysica Acta (BBA) - Biomembrane, vol. 1066, no. 2, pp. 166-174, 1991.

[26] R. Hielscher, T. Wenz, C. Hunte, and P. Hellwig, "Monitoring the redox and protonation dependent contributions of cardiolipin in electrochemically induced FTIR difference spectra of the cytochrome bcl complex from yeast," Biochimica et Biophysica Acta (BBA) - Bioenergetics, vol. 1787, no. 6, pp. 617-625, 2009.

[27] M. Dahlberg, A. Marini, B. Mennucci, and A. Maliniak, "Quantum chemical modeling of the cardiolipin headgroup," The Journal of Physical Chemistry A, vol. 114, no. 12, pp. 4375-4387, 2010.

[28] G. Olofsson and E. Sparr, "Ionization constants $\mathrm{pK}_{\mathrm{a}}$ of cardiolipin," PLoS ONE, vol. 8, no. 9, article e73040, 2013.

[29] J. M. Seddon, R. D. Kaye, and D. Marsh, "Induction of the lamellar-inverted hexagonal phase transition in cardiolipin by protons and monovalent cations," Biochimica et Biophysica Acta (BBA) - Biomembranes, vol. 734, no. 2, pp. 347352, 1983.

[30] E. E. Kooijman, L. A. Swim, Z. T. Graber, Y. Y. Tyurina, H. Bayır, and V. E. Kagan, "Magic angle spinning 31P NMR spectroscopy reveals two essentially identical ionization states for the cardiolipin phosphates in phospholipid liposomes," Biochimica et Biophysica Acta (BBA) - Biomembranes, vol. 1859, no. 1, pp. 61-68, 2017.

[31] T. Róg, H. Martinez-Seara, N. Munck, M. Oresic, M. Karttunen, and I. Vattulainen, "Role of cardiolipins in the inner mitochondrial membrane: insight gained through atom-scale simulations," The Journal of Physical Chemistry $B$, vol. 113, no. 11, pp. 3413-3422, 2009.

[32] M. Dahlberg, "Polymorphic phase behavior of cardiolipin derivatives studied by coarse-grained molecular dynamics," The Journal of Physical Chemistry B, vol. 111, no. 25, pp. 7194-7200, 2007.

[33] S. Nichols-Smith, S. Y. Teh, and T. L. Kuhl, “Thermodynamic and mechanical properties of model mitochondrial membranes," Biochimica et Biophysica Acta (BBA) - Biomembranes, vol. 1663, no. 1-2, pp. 82-88, 2004.

[34] M. Dahlberg and A. Maliniak, "Molecular dynamics simulations of cardiolipin bilayers," The Journal of Physical Chemistry B, vol. 112, no. 37, pp. 11655-11663, 2008.

[35] D. Ardail, J. P. Privat, M. Egret-Charlier, C. Levrat, F. Lerme, and P. Louisot, "Mitochondrial contact sites. Lipid composition and dynamics," Journal of Biological Chemistry, vol. 265, no. 31, pp. 18797-18802, 1990.

[36] J. J. Krebs, H. Hauser, and E. Carafoli, "Asymmetric distribution of phospholipids in the inner membrane of beef heart mitochondria," Journal of Biological Chemistry, vol. 254, pp. 5309-5316, 1979.

[37] V. Raja and M. L. Greenberg, "The functions of cardiolipin in cellular metabolism-potential modifiers of the Barth syndrome phenotype," Chemistry and Physics of Lipids, vol. 179, pp. 49-56, 2014.

[38] M. Zhang, E. Mileykovskaya, and W. Dowhan, "Gluing the respiratory chain Together," Journal of Biological Chemistry, vol. 277, no. 46, pp. 43553-43556, 2002.
[39] K. Pfeiffer, V. Gohil, R. A. Stuart et al., "Cardiolipin stabilizes respiratory chain supercomplexes," Journal of Biological Chemistry, vol. 278, no. 52, pp. 52873-52880, 2003.

[40] T. H. Haines, "Anionic lipid headgroups as a protonconducting pathway along the surface of membranes: a hypothesis," Proceedings of the National Academy of Sciences, vol. 80, no. 1, pp. 160-164, 1983.

[41] T. H. Haines and N. A. Dencher, "Cardiolipin: a proton trap for oxidative phosphorylation," FEBS Letters, vol. 528, no. 13, pp. 35-39, 2002.

[42] C. Lange, J. H. Nett, B. L. Trumpower, and C. Hunte, "Specific roles of protein-phospholipid interactions in the yeast cytochrome $\mathrm{bc}_{1}$ complex structure," The EMBO Journal, vol. 20, no. 23, pp. 6591-6600, 2001.

[43] A. Namslauer and P. Brzezinski, "Structural elements involved in electron-coupled proton transfer in cytochrome c oxidase," FEBS Letters, vol. 567, no. 1, pp. 103-110, 2004.

[44] C. Arnarez, S. J. Marrink, and X. Periole, "Identification of cardiolipin binding sites on cytochrome $c$ oxidase at the entrance of proton channels," Scientific Reports, vol. 3, no. 1, 2013.

[45] M. Schlame and M. Ren, "Barth syndrome, a human disorder of cardiolipin metabolism," FEBS Letters, vol. 580, no. 23, pp. 5450-5455, 2006.

[46] A. Saric, K. Andreau, A. S. Armand, I. M. Møller, and P. X. Petit, "Barth Syndrome: from mitochondrial dysfunctions associated with aberrant production of reactive oxygen species to pluripotent stem cell studies," Frontiers in Genetics, vol. 6, p. 359, 2016.

[47] F. Gonzalvez, M. D'Aurelio, M. Boutant et al., "Barth syndrome: cellular compensation of mitochondrial dysfunction and apoptosis inhibition due to changes in cardiolipin remodeling linked to tafazzin (TAZ) gene mutation," Biochimica et Biophysica Acta (BBA) - Molecular Basis of Disease, vol. 1832, no. 8, pp. 1194-1206, 2013.

[48] G. Wang, M. L. McCain, L. Yang et al., "Modeling the mitochondrial cardiomyopathy of Barth syndrome with induced pluripotent stem cell and heart-on-chip technologies," Nature Medicine, vol. 20, no. 6, pp. 616-623, 2014.

[49] G. Paradies, V. Paradies, V. De Benedictis, F. M. Ruggiero, and G. Petrosillo, "Functional role of cardiolipin in mitochondrial bioenergetics," Biochimica et Biophysica Acta (BBA) - Bioenergetics, vol. 1837, no. 4, pp. 408-417, 2014.

[50] H. Yin and M. Zhu, "s," Free Radical Research, vol. 46, no. 8, pp. 959-974, 2012.

[51] J. J. Maguire, Y. Y. Tyurina, D. Mohammadyani et al., "Known unknowns of cardiolipin signaling: the best is yet to come," Biochimica et Biophysica Acta (BBA) - Molecular and Cell Biology of Lipids, vol. 1862, no. 1, pp. 8-24, 2017.

[52] C. T. Chu, J. Ji, R. K. Dagda et al., "Cardiolipin externalization to the outer mitochondrial membrane acts as an elimination signal for mitophagy in neuronal cells," Nature Cell Biology, vol. 15, no. 10, pp. 1197-1205, 2013.

[53] G. de Arriba, M. Calvino, S. Benito, and T. Parra, "Cyclosporine A-induced apoptosis in renal tubular cells is related to oxidative damage and mitochondrial fission," Toxicology Letters, vol. 218, no. 1, pp. 30-38, 2013.

[54] M. Garcia Fernandez, L. Troiano, L. Moretti et al., "Early changes in intramitochondrial cardiolipin distribution during apoptosis," Cell Growth \& Differentiation, vol. 13, no. 9, pp. $449-455,2002$. 
[55] F. Gonzalvez, Z. T. Schug, R. H. Houtkooper et al., "Cardiolipin provides an essential activating platform for caspase- 8 on mitochondria," Journal of Cell Biology, vol. 183, no. 4, pp. 681-696, 2008.

[56] O. Jalmar, L. François-Moutal, A. J. García-Sáez et al., "Caspase- 8 binding to cardiolipin in giant unilamellar vesicles provides a functional docking platform for Bid," PLoS ONE, vol. 8, no. 2, article e55250, 2013.

[57] M. Lutter, M. Fang, X. Luo, M. Nishijima, X. S. Xie, and $\mathrm{X}$. Wang, "Cardiolipin provides specificity for targeting of tBid to mitochondria," Nature Cell Biology, vol. 2, no. 10, pp. 754-756, 2000.

[58] M. D. Esposti, I. M. Cristea, S. J. Gaskell, Y. Nakao, and C. Dive, "Proapoptotic Bid binds to monolysocardiolipin, a new molecular connection between mitochondrial membranes and cell death," Cell Death \& Differentiation, vol. 10, no. 12, pp. 1300-1309, 2003.

[59] F. Gonzalvez, F. Pariselli, O. Jalmar et al., "Mechanistic issues of the interaction of the hairpin-forming domain of tBid with mitochondrial cardiolipin," PLOS ONE, vol. 5, no. 2, article e9342, 2010.

[60] P. X. Petit, P. Dupaigne, F. Pariselli et al., "Interaction of the alpha-helical H6 peptide from the pro-apoptotic protein $\mathrm{tBid}$ with cardiolipin," FEBS Journal, vol. 276, no. 21, pp. 63386354, 2009.

[61] E. Raemy and J. C. Martinou, "Involvement of cardiolipin in tBID-induced activation of BAX during apoptosis," Chemistry and Physics of Lipids, vol. 179, pp. 70-74, 2014.

[62] M. Ott, J. D. Robertson, V. Gogvadze, B. Zhivotovsky, and S. Orrenius, "Cytochrome c release from mitochondria proceeds by a two-step process," Proceedings of the National Academy of Sciences, vol. 99, no. 3, pp. 1259-1263, 2002.

[63] P. Li, D. Nijhawan, I. Budihardjo et al., "Cytochrome c and dATP-dependent formation of Apaf-1/caspase-9 complex initiates an apoptotic protease cascade," Cell, vol. 91, no. 4, pp. 479-489, 1997.

[64] H. Zou, Y. Li, X. Liu, and X. Wang, "An APAF-1.cytochrome c multimeric complex is a functional apoptosome that activates procaspase-9," Journal of Biological Chemistry, vol. 274, no. 17, pp. 11549-11556, 1999.

[65] H. Bayir, B. Fadeel, M. J. Palladino et al., "Apoptotic interactions of cytochrome c: redox flirting with anionic phospholipids within and outside of mitochondria," Biochimica et Biophysica Acta (BBA) - Bioenergetics, vol. 1757, no. 5-6, pp. 648-659, 2006.

[66] A. Kumar, D. Ganini, and R. P. Mason, "Role of cytochrome $c$ in $\alpha$-synuclein radical formation: implications of $\alpha$-synuclein in neuronal death in Maneb- and paraquat-induced model of Parkinson's disease," Molecular Neurodegeneration, vol. 11, no. 1, pp. 70-82, 2016.

[67] C. A. Elena-Real, A. Díaz-Quintana, K. González-Arzola et al., "Cytochrome $c$ speeds up caspase cascade activation by blocking 14-3-3 $\varepsilon$-dependent Apaf-1 inhibition," Cell Death \& Disease, vol. 9, no. 3, pp. 365-377, 2018.

[68] J. Martínez-Fábregas, I. Díaz-Moreno, K. González-Arzola et al., "New Arabidopsis thaliana cytochrome c partners: a look into the elusive role of cytochrome c in programmed cell death in plants," Molecular \& Cellular Proteomics, vol. 12, no. 12, pp. 3666-3676, 2013.

[69] J. Martínez-Fábregas, I. Díaz-Moreno, K. González-Arzola, A. Díaz-Quintana, and M. A. De la Rosa, "A common signa- losome for programmed cell death in humans and plants," Cell Death \& Disease, vol. 5, no. 7, p. e1314, 2014.

[70] J. Martínez-Fábregas, I. Díaz-Moreno, K. González-Arzola et al., "Structural and functional analysis of novel human cytochrome c targets in apoptosis," Molecular \& Cellular Proteomics, vol. 13, no. 6, pp. 1439-1456, 2014.

[71] K. González-Arzola, I. Díaz-Moreno, A. Cano-González et al., "Structural basis for inhibition of the histone chaperone activity of SET/TAF-I $\beta$ by cytochrome c," Proceedings of the National Academy of Sciences, vol. 112, no. 32, pp. 99089913, 2015.

[72] K. González-Arzola, A. Díaz-Quintana, F. Rivero-Rodríguez, A. Velázquez-Campoy, M. A. de la Rosa, and I. Díaz-Moreno, "Histone chaperone activity of Arabidopsis thaliana NRP1 is blocked by cytochrome c," Nucleic Acids Research, vol. 45, no. 4, pp. 2150-2165, 2017.

[73] I. Díaz-Moreno, A. Velázquez-Cruz, S. Curran-French, A. Díaz-Quintana, and M. A. De la Rosa, "Nuclear cytochrome c - a mitochondrial visitor regulating damaged chromatin dynamics," FEBS Letters, vol. 592, no. 2, pp. 172-178, 2018.

[74] A. Nur-E-Kamal, S. R. Gross, Z. Pan, Z. Balklava, J. Ma, and L. F. Liu, "Nuclear translocation of cytochrome $c$ during apoptosis," Journal of Biological Chemistry, vol. 279, no. 24, pp. 24911-24914, 2004.

[75] R. Zalk, A. Israelson, E. S. Garty, H. Azoulay-Zohar, and V. Shoshan-Barmatz, "Oligomeric states of the voltagedependent anion channel and cytochrome c release from mitochondria," Biochemical Journal, vol. 386, no. 1, pp. 7383, 2005.

[76] F. Nolin, J. Michel, L. Wortham et al., "Stage-specific changes in the water, $\mathrm{Na}+, \mathrm{Cl}$ - and $\mathrm{K}+$ contents of organelles during apoptosis, demonstrated by a targeted cryo correlative analytical approach," PLoS ONE, vol. 11, no. 2, article e0148727, 2016.

[77] K. González-Arzola, A. Velázquez-Cruz, A. Guerra-Castellano et al., "New moonlighting functions of mitochondrial cytochrome $\mathrm{c}$ in the cytoplasm and nucleus," FEBS Letters, vol. 593, no. 22, pp. 3101-3119, 2019.

[78] I. Bertini, G. Cavallaro, and A. Rosato, "Cytochrome c: occurrence and functions," Chemical Reviews, vol. 106, no. 1, pp. 90-115, 2006.

[79] H. Maity, M. Maity, and S. Walter Englander, "How cytochrome c folds, and why: submolecular foldon units and their stepwise sequential stabilization," Journal of Molecular Biology, vol. 343, no. 1, pp. 223-233, 2004.

[80] V. Yin, G. S. Shaw, and L. Konermann, "Cytochromecas a peroxidase: activation of the precatalytic native state by $\mathrm{H}_{2} \mathrm{O}_{2}$-induced covalent modifications," Journal of the American Chemical Society, vol. 139, no. 44, pp. 15701-15709, 2017.

[81] R. E. Dickerson, T. Takano, D. Eisenberg et al., "Ferricytochrome c. I. General features of the horse and bonito proteins at 2.8 A resolution," Journal of Biological Chemistry, vol. 246, no. 5, pp. 1511-1535, 1971.

[82] W. H. Koppenol and E. Margoliash, "The asymmetric distribution of charges on the surface of horse cytochrome c. Functional implications," Journal of Biological Chemistry, vol. 257, no. 8, pp. 4426-4437, 1982.

[83] H. K. Kimelberg and C. P. Lee, "Binding and electron transfer to cytochrome c in artificial phospholipid membranes," 
Biochemical and Biophysical Research Communications, vol. 34, no. 6, pp. 784-790, 1969.

[84] P. J. R. Spooner and A. Watts, "Reversible unfolding of cytochrome $\mathrm{c}$ upon interaction with cardiolipin bilayers. I. Evidence from deuterium NMR measurements," Biochemistry, vol. 30, no. 16, pp. 3871-3879, 1991.

[85] P. J. Spooner, A. A. Duralski, S. E. Rankin, T. J. Pinheiro, and A. Watts, "Dynamics in a protein-lipid complex: nuclear magnetic resonance measurements on the headgroup of cardiolipin when bound to cytochrome c," Biophysical Journal, vol. 65, no. 1, pp. 106-112, 1993.

[86] Z. Salamon and G. Tollin, "Interaction of horse heart cytochrome $c$ with lipid bilayer membranes: effects on redox potentials," Journal of Bioenergetics and Biomembranes, vol. 29, no. 3, pp. 211-221, 1997.

[87] Z. Salamon and G. Tollin, "Surface plasmon resonance studies of complex formation between cytochrome $\mathrm{c}$ and bovine cytochrome $\mathrm{c}$ oxidase incorporated into a supported planar lipid bilayer. II. Binding of cytochrome c to oxidasecontaining cardiolipin/phosphatidylcholine membranes," Biophysical Journal, vol. 71, no. 2, pp. 858-867, 1996.

[88] Z. Salamon and G. Tollin, "Surface plasmon resonance studies of complex formation between cytochrome $\mathrm{c}$ and bovine cytochrome $\mathrm{c}$ oxidase incorporated into a supported planar lipid bilayer. I. Binding of cytochrome $\mathrm{c}$ to cardiolipin/phosphatidylcholine membranes in the absence of oxidase," Biophysical Journal, vol. 71, no. 2, pp. 848-857, 1996.

[89] I. L. Nantes, M. R. Zucchi, O. R. Nascimento, and A. FaljoniAlario, "Effect of heme iron valence state on the conformation of cytochrome $\mathrm{c}$ and its association with membrane interfaces. A CD and EPR investigation," Journal of Biological Chemistry, vol. 276, no. 1, pp. 153-158, 2001.

[90] L. A. Pandiscia and R. Schweitzer-Stenner, "Coexistence of native-like and non-native partially unfolded ferricytochrome $\mathrm{c}$ on the surface of cardiolipin-containing liposomes," The Journal of Physical Chemistry B, vol. 119, no. 4, pp. 1334-1349, 2015.

[91] A. Kostrzewa, T. Páli, W. Froncisz, and D. Marsh, "Membrane location of spin-labeled cytochrome $\mathrm{c}$ determined by paramagnetic relaxation agents," Biochemistry, vol. 39, no. 20, pp. 6066-6074, 2000.

[92] M. Imai, T. Saio, H. Kumeta, T. Uchida, F. Inagaki, and K. Ishimori, "Investigation of the redox-dependent modulation of structure and dynamics in human cytochrome $c$," Biochemical and Biophysical Research Communications, vol. 469, no. 4, pp. 978-984, 2016.

[93] M. Rytomaa and P. K. Kinnunen, "Evidence for two distinct acidic phospholipid-binding sites in cytochrome c," Journal of Biological Chemistry, vol. 269, no. 3, pp. 17701774, 1994.

[94] M. Rytomaa and P. K. J. Kinnunen, "Reversibility of the binding of cytochrome $\mathrm{c}$ to liposomes. Implications for lipidprotein interactions," Journal of Biological Chemistry, vol. 270, no. 7, pp. 3197-3202, 1995.

[95] E. K. J. Tuominen, K. Zhu, C. J. A. Wallace et al., “ATP induces a conformational change in lipid-bound cytochrome c," Journal of Biological Chemistry, vol. 276, no. 22, pp. 19356-19362, 2001.

[96] E. K. J. Tuominen, C. J. A. Wallace, and P. K. J. Kinnunen, "Phospholipid-CytochromecInteraction," Journal of Biological Chemistry, vol. 277, no. 11, pp. 8822-8826, 2002.
[97] F. Sinibaldi, B. D. Howes, M. C. Piro et al., "Extended cardiolipin anchorage to cytochrome c: a model for proteinmitochondrial membrane binding," JBIC Journal of Biological Inorganic Chemistry, vol. 15, no. 5, pp. 689-700, 2010.

[98] C. Kawai, F. M. Prado, G. L. C. Nunes, P. di Mascio, A. M. Carmona-Ribeiro, and I. L. Nantes, "pH-dependent interaction of cytochrome $c$ with mitochondrial mimetic membranes: the role of an array of positively charged amino acids," Journal of Biological Chemistry, vol. 280, no. 41, pp. 34709-34717, 2005.

[99] E. Kalanxhi and C. J. A. Wallace, "Cytochrome c impaled: investigation of the extended lipid anchorage of a soluble protein to mitochondrial membrane models," Biochem J, vol. 407, no. 2, pp. 179-187, 2007.

[100] L. Banci, I. Bertini, H. B. Gray et al., "Solution structure of oxidized horse heart cytochrome c," Biochemistry, vol. 36, no. 32, pp. 9867-9877, 1997.

[101] F. Sinibaldi, B. D. Howes, E. Droghetti et al., "Role of lysines in cytochrome c-cardiolipin interaction," Biochemistry, vol. 52, no. 26, pp. 4578-4588, 2013.

[102] M. Abe, R. Niibayashi, S. Koubori, I. Moriyama, and H. Miyoshi, "Molecular mechanisms for the induction of peroxidase activity of the cytochrome c-cardiolipin complex," Biochemistry, vol. 50, no. 39, pp. 8383-8391, 2011.

[103] J. Hanske, J. R. Toffey, A. M. Morenz, A. J. Bonilla, K. H. Schiavoni, and E. V. Pletneva, "Conformational properties of cardiolipin-bound cytochrome c," Proceedings of the National Academy of Sciences, vol. 109, no. 1, pp. 125-130, 2012.

[104] J. Hong, K. Huang, W. Wang et al., "Direct electrochemistry of artificial peroxidase based on self-assembled cytochrome c-sds-nano-micelle," Analytical Letters, vol. 45, no. 15, pp. 2221-2235, 2012.

[105] A. A. Kapralov, I. V. Kurnikov, I. I. Vlasova et al., "The hierarchy of structural transitions induced in cytochrome $\mathrm{c}$ by anionic phospholipids determines its peroxidase activation and selective peroxidation during apoptosis in cells," Biochemistry, vol. 46, no. 49, pp. 14232-14244, 2007.

[106] R. Jemmerson, J. Liu, D. Hausauer, K. P. Lam, A. Mondino, and R. D. Nelson, "A conformational change in cytochrome $\mathrm{c}$ of apoptotic and necrotic cells is detected by monoclonal antibody binding and mimicked by association of the native antigen with synthetic phospholipid vesicles," Biochemistry, vol. 38, no. 12, pp. 3599-3609, 1999.

[107] M. Assfalg, I. Bertini, A. Dolfi et al., "Structural model for an alkaline form of ferricytochrome c," Journal of the American Chemical Society, vol. 125, no. 10, pp. 2913-2922, 2003.

[108] S. Hirota, Y. Hattori, S. Nagao et al., "Cytochrome c polymerization by successive domain swapping at the C-terminal helix," Proceedings of the National Academy of Sciences, vol. 107, no. 29, pp. 12854-12859, 2010.

[109] S. Hirota, N. Yamashiro, Z. Wang, and S. Nagao, "Effect of methionine80 heme coordination on domain swapping of cytochrome c," JBIC Journal of Biological Inorganic Chemistry, vol. 22, no. 5, pp. 705-712, 2017.

[110] L. J. McClelland, H. B. B. Steele, F. G. Whitby et al., "Cytochrome $\mathrm{c}$ can form a well-defined binding pocket for hydrocarbons," Journal of the American Chemical Society, vol. 138, no. 51, pp. 16770-16778, 2016.

[111] S. M. Kapetanaki, G. Silkstone, I. Husu, U. Liebl, M. T. Wilson, and M. H. Vos, "Interaction of carbon monoxide with 
the apoptosis-inducing cytochrome c-cardiolipin complex," Biochemistry, vol. 48, no. 7, pp. 1613-1619, 2009.

[112] J. Muenzner, J. R. Toffey, Y. Hong, and E. V. Pletneva, "Becoming a peroxidase: cardiolipin-induced unfolding of cytochrome c," The Journal of Physical Chemistry B, vol. 117, no. 42, pp. 12878-12886, 2013.

[113] L. V. Basova, I. V. Kurnikov, L. Wang et al., "Cardiolipin switch in mitochondria: shutting off the reduction of cytochrome $\mathrm{c}$ and turning on the peroxidase activity," Biochemistry, vol. 46, no. 11, pp. 3423-3434, 2007.

[114] J. M. Bradley, G. Silkstone, M. T. Wilson, M. R. Cheesman, and J. N. Butt, "Probing a complex of cytochrome $\mathrm{c}$ and cardiolipin by magnetic circular dichroism spectroscopy: implications for the initial events in apoptosis," Journal of the American Chemical Society, vol. 133, no. 49, pp. 1967619679, 2011.

[115] E. S. O'Brien, N. V. Nucci, B. Fuglestad, C. Tommos, and A. J. Wand, "Defining the apoptotic trigger the interaction of cytochrome c and cardiolipin," Journal of Biological Chemistry, vol. 290, no. 52, pp. 30879-30887, 2015.

[116] I. Díaz-Moreno, J. M. García-Heredia, A. Díaz-Quintana, and M. A. De la Rosa, "Cytochrome c signalosome in mitochondria," European Biophysics Journal, vol. 40, no. 12, pp. 1301-1315, 2011.

[117] I. Díaz-Moreno, A. Díaz-Quintana, M. Ubbink, and M. A. De la Rosa, "An NMR-based docking model for the physiological transient complex between cytochrome $\mathrm{f}$ and cytochrome c6," FEBS Letters, vol. 579, no. 13, pp. 2891-2896, 2005.

[118] A. Mandal, C. L. Hoop, M. DeLucia et al., "Structural Changes and Proapoptotic Peroxidase Activity of Cardiolipin-Bound Mitochondrial Cytochrome c," Biophysical Journal, vol. 109, no. 9, pp. 1873-1884, 2015.

[119] D. Mohammadyani, N. Yanamala, A. K. Samhan-Arias et al., "Structural characterization of cardiolipin-driven activation of cytochrome $\mathrm{c}$ into a peroxidase and membrane perturbation," Biochimica et Biophysica Acta (BBA) - Biomembrane, vol. 1860, no. 5, pp. 1057-1068, 2018.

[120] G. P. Gorbenko, J. G. Molotkovsky, and P. K. J. Kinnunen, "Cytochrome c interaction with cardiolipin/phosphatidylcholine model membranes: effect of cardiolipin protonation," Biophysical Journal, vol. 90, no. 11, pp. 40934103, 2006.

[121] J. B. Robinson Jr., J. M. Strottmann, and E. Stellwagen, “A globular high spin form of ferricytochrome c," Journal of Biological Chemistry, vol. 258, no. 11, pp. 6772-6776, 1983.

[122] P. Tonge, G. R. Moore, and C. W. Wharton, "Fourier-transform infra-red studies of the alkaline isomerization of mitochondrial cytochrome $\mathrm{c}$ and the ionization of carboxylic acids," Biochemical Journal, vol. 258, no. 2, pp. 599-605, 1989.

[123] R. Schweitzer-Stenner, "Internal electric field in cytochrome c explored by visible electronic circular dichroism spectroscopy," The Journal of Physical Chemistry B, vol. 112, no. 33, pp. 10358-10366, 2008.

[124] L. A. Pandiscia and R. Schweitzer-Stenner, "Salt as a catalyst in the mitochondria: returning cytochrome $c$ to its native state after it misfolds on the surface of cardiolipin containing membranes," Chemical Communications, vol. 50, no. 28, pp. 3674-3676, 2014.

[125] S. Oellerich, S. Lecomte, M. Paternostre, T. Heimburg, and P. Hildebrandt, "Peripheral and integral binding of Cyto- chromecto phospholipids vesicles," The Journal of Physical Chemistry B, vol. 108, no. 12, pp. 3871-3878, 2004.

[126] S. Oellerich, H. Wackerbarth, and P. Hildebrandt, "Spectroscopic characterization of nonnative conformational states of Cytochromec," The Journal of Physical Chemistry B, vol. 106, no. 25, pp. 6566-6580, 2002.

[127] B. Milorey, D. Malyshka, and R. Schweitzer-Stenner, "pH dependence of ferricytochrome c conformational transitions during binding to cardiolipin membranes: evidence for histidine as the distal ligand at neutral $\mathrm{pH}$," The Journal of Physical Chemistry, vol. 8, no. 9, pp. 1993-1998, 2017.

[128] R. Schweitzer-Stenner, "Relating the multi-functionality of cytochrome c to membrane binding and structural conversion," Biophysical Reviews, vol. 10, no. 4, pp. 1151-1185, 2018.

[129] A. Ranieri, D. Millo, G. di Rocco et al., "Immobilized cytochrome $\mathrm{c}$ bound to cardiolipin exhibits peculiar oxidation state-dependent axial heme ligation and catalytically reduces dioxygen," JBIC Journal of Biological Inorganic Chemistry, vol. 20, no. 3, pp. 531-540, 2015.

[130] D. A. Capdevila, S. Oviedo Rouco, F. Tomasina et al., "Active site structure and peroxidase activity of oxidatively modified cytochrome c species in complexes with cardiolipin," Biochemistry, vol. 54, no. 51, pp. 7491-7504, 2015.

[131] Y. Hong, J. Muenzner, S. K. Grimm, and E. V. Pletneva, “Origin of the conformational heterogeneity of cardiolipin-bound cytochrome c," ournal of the American Chemical Society, vol. 134, no. 45, pp. 18713-18723, 2012.

[132] P. J. R. Spooner and A. Watts, "Cytochrome c interactions with cardiolipin in bilayers: a multinuclear magic-angle spinning NMR study," Biochemistry, vol. 31, no. 41, pp. 1012910138, 1992.

[133] A. Rietveld, P. Sijens, A. J. Verkleij, and B. de Kruijff, "Interaction of cytochrome $\mathrm{c}$ and its precursor apocytochrome $\mathrm{c}$ with various phospholipids," EMBO Journal, vol. 2, no. 6, pp. 907-913, 1983.

[134] B. de Kruijff and P. R. Cullis, "Cytochrome c specifically induces non-bilayer structures in cardiolipin- containing model membranes," Biochimica et Biophysica Acta (BBA) Biomembranes, vol. 602, no. 3, pp. 477-490, 1980.

[135] L. R. Brown and K. Wüthrich, "NMR and ESR studies of the interactions of cytochrome $\mathrm{c}$ with mixed cardiolipinphosphatidylcholine vesicles," Biochimica et Biophysica Acta (BBA) - Biomembranes, vol. 468, no. 3, pp. 389-410, 1977.

[136] T. J. T. Pinheiro and A. Watts, "Lipid specificity in the interaction of cytochrome $c$ with anionic phospholipid bilayers revealed by solid-state ${ }^{31} \mathrm{P}$ NMR," Biochemistry, vol. 33, no. 9, pp. 2451-2458, 1994.

[137] C. L. Bergstrom, P. A. Beales, Y. Lv, T. K. Vanderlick, and J. T. Groves, "Cytochrome c causes pore formation in cardiolipincontaining membranes," Proceedings of the National Academy of Sciences, vol. 110, no. 16, pp. 6269-6274, 2013.

[138] M. Li, A. Mandal, V. A. Tyurin et al., "Surface-binding to cardiolipin nanodomains triggers cytochrome $\mathrm{c}$ pro-apoptotic peroxidase activity via localized dynamics," Structure, vol. 27, no. 5, pp. 806-815.e4, 2019.

[139] G. G. Borisenko, A. A. Kapralov, V. A. Tyurin, A. Maeda, D. A. Stoyanovsky, and V. E. Kagan, "Molecular design of new inhibitors of peroxidase activity of cytochrome c/cardiolipin complexes: fluorescent oxadiazole-derivatized cardiolipin," Biochemistry, vol. 47, no. 51, pp. 13699-13710, 2008. 
[140] P. Ascenzi, M. Marino, F. Polticelli, R. Santucci, and M. Coletta, "Cardiolipin modulates allosterically the nitrite reductase activity of horse heart cytochrome c," BIC Journal of Biological Inorganic Chemistry, vol. 19, no. 7, pp. 11951201, 2014.

[141] H. Yin and M. Zhu, "Free radical oxidation of cardiolipin: chemical mechanisms, detection and implication in apoptosis, mitochondrial dysfunction and human diseases," Free Radical Research, vol. 46, no. 8, pp. 959-974, 2012.

[142] H. Yin, L. Xu, and N. A. Porter, "Free radical lipid peroxidation: mechanisms and analysis," Chemical Reviews, vol. 111, no. 10, pp. 5944-5972, 2011.

[143] H. P. Indo, H.-C. Yen, I. Nakanishi et al., "A mitochondrial superoxide theory for oxidative stress diseases and aging," Journal of Clinical Biochemistry and Nutrition, vol. 56, no. 1, pp. 1-7, 2015.

[144] C. Michiels, M. Raes, O. Toussaint, and J. Remacle, "Importance of SE-glutathione peroxidase, catalase, and CU/ZNSOD for cell survival against oxidative stress," Free Radical Biology and Medicine, vol. 17, no. 3, pp. 235-248, 1994.

[145] R. Radi, L. Thomson, H. Rubbo, and E. Prodanov, "Cytochrome c-catalyzed oxidation of organic molecules by hydrogen peroxide," Archives of Biochemistry and Biophysics, vol. 288, no. 1, pp. 112-117, 1991.

[146] R. Radi, J. F. Turrens, and B. A. Freeman, "Cytochrome ccatalyzed membrane lipid peroxidation by hydrogen peroxide," Archives of Biochemistry and Biophysics, vol. 288, no. 1, pp. 118-125, 1991.

[147] J. Dawson, "Probing structure-function relations in hemecontaining oxygenases and peroxidases," Science, vol. 240, no. 4851, pp. 433-439, 1988.

[148] I. Vlasova, "Peroxidase activity of human hemoproteins: keeping the fire under control," Molecules, vol. 23, no. 10, p. 2561, 2018.

[149] N. A. Belikova, Y. Y. Tyurina, G. Borisenko et al., "Heterolytic reduction of fatty acid hydroperoxides by cytochrome c/cardiolipin complexes: antioxidant function in mitochondria," Journal of the American Chemical Society, vol. 131, no. 32, pp. 11288-11289, 2009.

[150] L. J. Marnett, "Cyclooxygenase mechanisms," Current Opinion in Chemical Biology, vol. 4, no. 5, pp. 545-552, 2000.

[151] S. Y. Qian, Y. R. Chen, L. J. Deterding et al., "Identification of protein-derived tyrosyl radical in the reaction of cytochrome $\mathrm{c}$ and hydrogen peroxide: characterization by ESR spin-trapping, HPLC and MS," Biochemical Journal, vol. 363, no. 2, pp. 281-288, 2002.

[152] U. Barayeu, M. Lange, L. Méndez et al., "Cytochrome c autocatalyzed carbonylation in the presence of hydrogen peroxide and cardiolipins," Journal of Biological Chemistry, vol. 294, no. 6, pp. 1816-1830, 2019.

[153] T. L. Poulos and J. Kraut, "The stereochemistry of peroxidase catalysis," Journal of Biological Chemistry, vol. 255, no. 17, pp. 8199-8205, 1980.

[154] L. Banci, P. Carloni, A. Díaz, and G. G. Savellini, "Molecular dynamics calculations on peroxidases: the effect of calcium ions on protein structure," JBIC Journal of Biological Inorganic Chemistry, vol. 1, no. 3, pp. 264-272, 1996.

[155] A. Lawrence, C. M. Jones, P. Wardman, and M. J. Burkitt, "Evidence for the role of a peroxidase compound I-type intermediate in the oxidation of glutathione, $\mathrm{NADH}$, ascorbate, and dichlorofluorescin by cytochrome $\mathrm{c} / \mathrm{H}_{2} \mathrm{O}_{2}$. Implications for oxidative stress during apoptosis," Journal of Biological Chemistry, vol. 278, no. 32, pp. 29410-29419, 2003.

[156] E. Cadenas, A. I. Varsavsky, B. Alberto, and C. Britton, "Low level chemiluminescence of the cytochrome c-catalyzed decomposition of hydrogen peroxide," FEBS Letters, vol. 113, no. 2, pp. 141-144, 1980.

[157] D. P. Barr and R. P. Mason, "Mechanism of radical production from the reaction of cytochrome $c$ with organic hydroperoxides. An ESR spin trapping investigation," Journal of Biological Chemistry, vol. 270, no. 21, pp. 1270912716, 1995.

[158] D. P. Barr, M. R. Gunther, L. J. Deterding, K. B. Tomer, and R. P. Mason, "ESR spin-trapping of a protein-derived tyrosyl radical from the reaction of cytochrome $\mathrm{c}$ with hydrogen peroxide," Journal of Biological Chemistry, vol. 271, no. 26, pp. 15498-15503, 1996.

[159] B. S. Rajagopal, A. N. Edzuma, M. A. Hough et al., "The hydrogen-peroxide-induced radical behaviour in human cytochrome c-phospholipid complexes: implications for the enhanced pro-apoptotic activity of the G41S mutant," Biochemical Journal, vol. 456, no. 3, pp. 441-452, 2013.

[160] M. W. Mara, R. G. Hadt, M. E. Reinhard et al., "Metalloprotein entatic control of ligand-metal bonds quantified by ultrafast X-ray spectroscopy," Science, vol. 356, no. 6344, pp. 1276-1280, 2017.

[161] R. E. M. Diederix, M. Ubbink, and G. W. Canters, "Peroxidase activity as a tool for studying the folding of c-type cytochromes," Biochemistry, vol. 41, no. 43, pp. 13067-13077, 2002.

[162] N. Tomaskova, R. Varhac, V. Lysakova, A. Musatov, and E. Sedlak, "Peroxidase activity of cytochrome $\mathrm{c}$ in its compact state depends on dynamics of the heme region," Biochimica et Biophysica Acta (BBA) - Proteins and Proteomics, vol. 1866, no. 11, pp. 1073-1083, 2018.

[163] P. Ascenzi, M. Coletta, M. T. Wilson et al., "Cardiolipin-cytochrome c complex: switching cytochrome $\mathrm{c}$ from an electrontransfer shuttle to a myoglobin- and a peroxidase-like hemeprotein," IUBMB Life, vol. 67, no. 2, pp. 98-109, 2015.

[164] M. Velayutham, C. F. Hemann, A. J. Cardounel, and J. L. Zweier, "Sulfite oxidase activity of cytochrome c: role of hydrogen peroxide," Biochemistry and Biophysics Reports, vol. 5, pp. 96-104, 2016.

[165] H. Bayır, A. A. Kapralov, J. Jiang et al., "Peroxidase mechanism of lipid-dependent cross-linking of synuclein with cytochrome c: protection against apoptosis versus delayed oxidative stress in Parkinson disease," Journal of Biological Chemistry, vol. 284, no. 23, pp. 15951-15969, 2009.

[166] K. Nomura, H. Imai, T. Koumura, T. Kobayashi, and Y. Nakagawa, "Mitochondrial phospholipid hydroperoxide glutathione peroxidase inhibits the release of cytochrome $c$ from mitochondria by suppressing the peroxidation of cardiolipin in hypoglycaemia-induced apoptosis," Biochemical Journal, vol. 351, no. 1, pp. 183-193, 2000.

[167] V. E. Kagan, G. G. Borisenko, Y. Y. Tyurina et al., “Oxidative lipidomics of apoptosis: redox catalytic interactions of cytochrome c with cardiolipin and phosphatidylserine," Free Radical Biology and Medicine, vol. 37, no. 12, pp. 1963-1985, 2004.

[168] N. H. Kim, M. S. Jeong, S. Y. Choi, and J. H. Kang, "Oxidative modification of cytochrome c by hydrogen peroxide," Molecules and Cells, vol. 22, no. 2, pp. 220-227, 2006.

[169] A. D. Nugraheni, C. Ren, Y. Matsumoto, S. Nagao, M. Yamanaka, and S. Hirota, "Oxidative modification of 
methionine80 in cytochrome c by reaction with peroxides," Journal of Inorganic Biochemistry, vol. 182, pp. 200-207, 2018.

[170] V. Yin, S. H. Mian, and L. Konermann, "Lysine carbonylation is a previously unrecognized contributor to peroxidase activation of cytochromecby chloramine-T," Chemical Science, vol. 10, no. 8, pp. 2349-2359, 2019.

[171] R. D. Parakra, T. Kleffmann, G. N. L. Jameson, and E. C. Ledgerwood, "The proportion of Met80-sulfoxide dictates peroxidase activity of human cytochrome c," Dalton Transactions, vol. 47, no. 27, pp. 9128-9135, 2018.

[172] F. Zhong and E. V. Pletneva, "Ligation and reactivity of methionine-oxidized Cytochromec," Inorganic Chemistry, vol. 57, no. 10, pp. 5754-5766, 2018.

[173] S. Harel, M. A. Salan, and J. Kanner, "Iron release from metmyoglobin, methaemoglobin and cytochrome c by a system generating hydrogen peroxide," Free Radical Research Communications, vol. 5, no. 1, pp. 11-19, 1998.

[174] D. A. Capdevila, W. A. Marmisollé, F. Tomasina et al., "Specific methionine oxidation of cytochrome $c$ in complexes with zwitterionic lipids by hydrogen peroxide: potential implications for apoptosis," Chemical Science, vol. 6, no. 1, pp. 705-713, 2015.

[175] L. C. Godoy, C. Muñoz-Pinedo, L. Castro et al., "Disruption of the M80-Fe ligation stimulates the translocation of cytochrome $\mathrm{c}$ to the cytoplasm and nucleus in nonapoptotic cells," Proceedings of the National Academy of Sciences, vol. 106, no. 8, pp. 2653-2658, 2009.

[176] L. J. McClelland, T.-C. Mou, M. E. Jeakins-Cooley, S. R. Sprang, and B. E. Bowler, "Structure of a mitochondrial cytochrome c conformer competent for peroxidase activity," Proceedings of the National Academy of Sciences, vol. 111, no. 18, pp. 6648-6653, 2014.

[177] G. Balakrishnan, Y. Hu, O. F. Oyerinde, J. Su, J. T. Groves, and T. G. Spiro, "A conformational switch to $\beta$-sheet structure in cytochrome $c$ leads to heme exposure. Implications for cardiolipin peroxidation and apoptosis," Journal of the American Chemical Society, vol. 129, no. 3, pp. 504-505, 2007.

[178] J. M. García-Heredia, A. Díaz-Quintana, M. Salzano et al., "Tyrosine phosphorylation turns alkaline transition into a biologically relevant process and makes human cytochrome c behave as an anti-apoptotic switch," JBIC Journal of Biological Inorganic Chemistry, vol. 16, no. 8, pp. 1155-1168, 2011.

[179] L. A. Abriata, A. Cassina, V. Tórtora et al., "Nitration of solvent-exposed tyrosine 74 on CytochromecTriggers heme iron-methionine 80 bond disruption," Journal of Biological Chemistry, vol. 284, no. 1, pp. 17-26, 2008.

[180] A. M. Cassina, R. Hodara, J. M. Souza et al., "Cytochrome c nitration by peroxynitrite," Journal of Biological Chemistry, vol. 275, no. 28, pp. 21409-21415, 2000.

[181] O. M. Deacon, D. A. Svistunenko, G. R. Moore, M. T. Wilson, and J. A. R. Worrall, "Naturally occurring disease-related mutations in the 40-57 $\Omega$-loop of human cytochrome c control triggering of the alkaline isomerization," Biochemistry, vol. 57, no. 29, pp. 4276-4288, 2018.

[182] S. M. Nold, H. Lei, T. C. Mou, and B. E. Bowler, "Effect of a K72A mutation on the structure, stability, dynamics, and peroxidase activity of human cytochrome c," Biochemistry, vol. 56, no. 26, pp. 3358-3368, 2017.

[183] J. A. R. Worrall, A. M. M. van Roon, M. Ubbink, and G. W. Canters, "The effect of replacing the axial methionine ligand with a lysine residue in cytochrome c-550 from Paracoccus versutus assessed by X-ray crystallography and unfolding," FEBS Journal, vol. 272, no. 10, pp. 2441-2455, 2005.

[184] I. Díaz-Moreno, J. M. García-Heredia, A. Díaz-Quintana, M. Teixeira, and M. A. De la Rosa, "Nitration of tyrosines 46 and 48 induces the specific degradation of cytochrome c upon change of the heme iron state to high-spin," Biochimica et Biophysica Acta (BBA) - Bioenergetics, vol. 1807, no. 12, pp. 1616-1623, 2011.

[185] J. M. García-Heredia, I. Díaz-Moreno, P. M. Nieto et al., "Nitration of tyrosine 74 prevents human cytochrome $\mathrm{c}$ to play a key role in apoptosis signaling by blocking caspase-9 activation," Biochimica et Biophysica Acta (BBA) - Bioenergetics, vol. 1797, no. 6-7, pp. 981-993, 2010.

[186] A. Guerra-Castellano, A. Díaz-Quintana, B. Moreno-Beltrán et al., "Mimicking tyrosine phosphorylation in human cytochrome cby the evolved tRNA synthetase technique," Chemistry, vol. 21, no. 42, pp. 15004-15012, 2015.

[187] K. M. Ivanetich, J. J. Bradshaw, and L. S. Kaminsky, "Methionine sulfoxide cytochrome c," Biochemistry, vol. 15, no. 5, pp. 1144-1153, 1976.

[188] H. Jakubowski, "Protein homocysteinylation: possible mechanism underlying pathological consequences of elevated homocysteine levels," FASEB Journal, vol. 13, no. 15, pp. 2277-2283, 1999.

[189] H. A. Kalpage, J. Wan, P. T. Morse et al., "Cytochrome c phosphorylation: control of mitochondrial electron transport chain flux and apoptosis," The International Journal of Biochemistry \& Cell Biology, vol. 121, p. 105704, 2020.

[190] P. Pecina, G. G. Borisenko, N. A. Belikova et al., "Phosphomimetic substitution of cytochrome $c$ tyrosine 48 decreases respiration and binding to cardiolipin and abolishes ability to trigger downstream caspase activation," Biochemistry, vol. 49 , no. 31, pp. 6705-6714, 2010.

[191] B. M. K. Gmeiner and C. C. C. Seelos, "Tyrosine phosphorylation blocks tyrosine free radical formation and, hence, the hormonogenic iodination reaction," Free Radical Biology and Medicine, vol. 21, no. 3, pp. 349-351, 1996.

[192] A. Guerra-Castellano, I. Díaz-Moreno, A. Velázquez-Campoy, M. A. De la Rosa, and A. Díaz-Quintana, "Structural and functional characterization of phosphomimetic mutants of cytochrome c at threonine 28 and serine 47," Biochimica et Biophysica Acta (BBA) - Bioenergetics, vol. 1857, no. 4, pp. 387-395, 2016.

[193] A. Guerra-Castellano, A. Díaz-Quintana, G. Pérez-Mejías et al., "Oxidative stress is tightly regulated by cytochromecphosphorylation and respirasome factors in mitochondria," Proceedings of the National Academy of Sciences, vol. 115, no. 31, pp. 7955-7960, 2018.

[194] B. Moreno-Beltrán, A. Guerra-Castellano, A. Díaz-Quintana et al., "Structural basis of mitochondrial dysfunction in response to cytochromecphosphorylation at tyrosine 48," Proceedings of the National Academy of Sciences, vol. 114, no. 15, pp. E3041-E3050, 2017.

[195] G. Mahapatra, A. Varughese, Q. Ji et al., "Phosphorylation of cytochrome $\mathrm{c}$ threonine 28 regulates electron transport chain activity in kidney: implications for AMP kinase," Journal of Biological Chemistry, vol. 292, no. 1, pp. 64-79, 2017.

[196] R. K. Shervedani and M. S. Foroushani, "Direct electrochemistry of cytochrome c immobilized on gold electrode surface via $\mathrm{Zr}(\mathrm{IV})$ ion glue and its activity for ascorbic acid," Bioelectrochemistry, vol. 98, pp. 53-63, 2014. 
[197] C. Batthyány, J. M. Souza, R. Durán, A. Cassina, C. Cerveñansky, and R. Radi, "Time course and site(s) of cytochrome $c$ tyrosine nitration by peroxynitritet," Biochemistry, vol. 44, no. 22, pp. 8038-8046, 2005.

[198] T. Hasan, R. Arora, A. K. Bansal, R. Bhattacharya, G. S. Sharma, and L. R. Singh, "Disturbed homocysteine metabolism is associated with cancer," Experimental \& Molecular Medicine, vol. 51, no. 2, pp. 1-13, 2019.

[199] I. M. Morison, E. M. Cramer Bordé, E. J. Cheesman et al., “A mutation of human cytochrome $c$ enhances the intrinsic apoptotic pathway but causes only thrombocytopenia," Nature Genetics, vol. 40, no. 4, pp. 387-389, 2008.

[200] D. de Rocco, C. Cerqua, P. Goffrini et al., "Mutations of cytochrome c identified in patients with thrombocytopenia THC4 affect both apoptosis and cellular bioenergetics," Biochimica et Biophysica Acta (BBA) - Molecular Basis of Disease, vol. 1842, no. 2, pp. 269-274, 2014.

[201] B. Alvarez and R. Radi, "Peroxynitrite reactivity with amino acids and proteins," Amino Acids, vol. 25, no. 3-4, pp. 295311, 2003.

[202] I. Díaz-Moreno, P. M. Nieto, R. del Conte et al., "A nondamaging method to analyze the configuration and dynamics of nitrotyrosines in proteins," Chemistry, vol. 18, no. 13, pp. 3872-3878, 2012.

[203] V. Rodríguez-Roldán, J. M. García-Heredia, J. A. Navarro, M. A. De la Rosa, and M. Hervás, "Effect of nitration on the physicochemical and kinetic features of wild-type and monotyrosine mutants of human respiratory Cytochromec $\dagger$," Biochemistry, vol. 47, no. 47, pp. 12371-12379, 2008.

[204] J. M. García-Heredia, I. Díaz-Moreno, A. Díaz-Quintana et al., "Specific nitration of tyrosines 46 and 48 makes cytochrome c assemble a non-functional apoptosome," FEBS Letters, vol. 586, no. 2, pp. 154-158, 2012.

[205] H. K. Ly, T. Utesch, I. Díaz-Moreno, J. M. García-Heredia, M. A. De La Rosa, and P. Hildebrandt, "Perturbation of the redox site structure of cytochrome c variants upon tyrosine nitration," The Journal of Physical Chemistry B, vol. 116, no. 19, pp. 5694-5702, 2012.

[206] L. A. MacMillan-Crow, D. L. Cruthirds, K. M. Ahki, P. W. Sanders, and J. A. Thompson, "Mitochondrial tyrosine nitration precedes chronic allograft nephropathy," Free Radical Biology and Medicine, vol. 31, no. 12, pp. 16031608, 2001.

[207] J. Beltowski, "Protein homocysteinylation: a new mechanism of atherogenesis?," Postępy Higieny i Medycyny Doświadczalnej, vol. 59, pp. 392-404, 2005.

[208] J. Perła-Kaján, L. Marczak, Ł. Kaján, P. Skowronek, T. Twardowski, and H. Jakubowski, "Modification by homocysteine thiolactone affects redox status of cytochrome c," Biochemistry, vol. 46, no. 21, pp. 6225-6231, 2007.

[209] G. S. Sharma and L. R. Singh, "Conformational status of cytochrome c upon N-homocysteinylation: implications to cytochrome c release," Archives of Biochemistry and Biophysics, vol. 614, pp. 23-27, 2017.

[210] Z. Wang, Y. Ando, A. D. Nugraheni, C. Ren, S. Nagao, and S. Hirota, "Self-oxidation of cytochrome $c$ at methionine80 with molecular oxygen induced by cleavage of the Metheme iron bond," Molecular BioSystems, vol. 10, no. 12, pp. 3130-3137, 2014.

[211] A. I. Karsisiotis, O. M. Deacon, M. T. Wilson et al., "Increased dynamics in the 40-57 $\Omega$-loop of the G41S variant of human cytochrome $c$ promote its pro-apoptotic conformation," Scientific Reports, vol. 6, no. 1, pp. 30447-30459, 2016.

[212] O. M. Deacon, A. I. Karsisiotis, T. Moreno-Chicano et al., "Heightened dynamics of the oxidized $\mathrm{Y} 48 \mathrm{H}$ variant of human CytochromecIncreases its peroxidatic activity," Biochemistry, vol. 56, no. 46, pp. 6111-6124, 2017.

[213] T. H. Sanderson, G. Mahapatra, P. Pecina et al., "Cytochrome c is tyrosine 97 phosphorylated by neuroprotective insulin treatment," PLoS ONE, vol. 8, no. 11, article e78627, 2013.

[214] M. Hashimoto, A. Takeda, L. J. Hsu, T. Takenouchi, and E. Masliah, "Role of Cytochromecas a stimulator of $\alpha$-synuclein aggregation in lewy body disease," Journal of Biological Chemistry, vol. 274, no. 41, pp. 28849-28852, 1999.

[215] N. Garrido-Mesa, A. Zarzuelo, and J. Gálvez, "Minocycline: far beyond an antibiotic," British Journal of Pharmacology, vol. 169, no. 2, pp. 337-352, 2013.

[216] T. M. Scarabelli, A. Stephanou, E. Pasini et al., "Minocycline inhibits caspase activation and reactivation, increases the ratio of XIAP to smac/DIABLO, and reduces the mitochondrial leakage of cytochrome c and smac/DIABLO," Journal of the American College of Cardiology, vol. 43, no. 5, pp. 865-874, 2004.

[217] A. Patriarca, F. Polticelli, M. C. Piro et al., "Conversion of cytochrome $\mathrm{c}$ into a peroxidase: inhibitory mechanisms and implication for neurodegenerative diseases," Archives of Biochemistry and Biophysics, vol. 522, no. 1, pp. 62-69, 2012.

[218] A. M. Firsov, E. A. Kotova, and Y. N. Antonenko, "Minocycline prevents peroxidative permeabilization of cardiolipincontaining bilayer lipid membranes mediated by cytochrome c," Biochemical and Biophysical Research Communications, vol. 507, no. 1-4, pp. 510-513, 2018.

[219] I. I. Vlasova, V. A. Tyurin, A. A. Kapralov et al., "Nitric oxide inhibits peroxidase activity of cytochrome c-cardiolipin complex and blocks cardiolipin oxidation," Journal of Biological Chemistry, vol. 281, no. 21, pp. 14554-14562, 2006.

[220] G. Silkstone, S. M. Kapetanaki, I. Husu, M. H. Vos, and M. T. Wilson, "Nitric oxide binding to the cardiolipin complex of ferric cytochrome c," Biochemistry, vol. 51, no. 34, pp. 6760-6766, 2012.

[221] R. Lagoa, A. K. Samhan-Arias, and C. Gutiérrez-Merino, “Correlation between the potency of flavonoids for cytochrome $\mathrm{c}$ reduction and inhibition of cardiolipin-induced peroxidase activity," BioFactors, vol. 43, no. 3, pp. 451-468, 2017.

[222] J. Atkinson, A. A. Kapralov, N. Yanamala et al., "A mitochondria-targeted inhibitor of cytochrome $c$ peroxidase mitigates radiation-induced death," Nature Communications, vol. 2, no. 1, 2011.

[223] A. Bakan, A. A. Kapralov, H. Bayir, F. Hu, V. E. Kagan, and I. Bahar, "Inhibition of peroxidase activity of Cytochromec: de novo compound discovery and validation," Molecular Pharmacology, vol. 88, no. 3, pp. 421-427, 2005.

[224] V. E. Kagan, H. A. Bayır, N. A. Belikova et al., "Cytochrome c/cardiolipin relations in mitochondria: a kiss of death," Free Radical Biology and Medicine, vol. 46, no. 11, pp. 1439-1453, 2009.

[225] Y. A. Vladimirov, E. V. Proskurnina, and A. V. Alekseev, "Molecular mechanisms of apoptosis. Structure of cytochrome c-cardiolipin complex," Biochemistry, vol. 78, no. 10, pp. 1086-1097, 2013. 